\title{
Global analysis of human-to-mouse intercellular RNA transfer in cell culture
}

\section{Sandipan Dasgupta ${ }^{1}$, Daniella Y. Dayagi ${ }^{1}$, Gal Haimovich ${ }^{1,4}$, Emanuel Wyler ${ }^{2}$, Tsviya Olender ${ }^{1}$,}

Robert H. Singer ${ }^{3}$, Markus Landthaler ${ }^{2}$, and Jeffrey E. Gerst ${ }^{1,4}$

${ }^{1}$ Dept of Molecular Genetics, Weizmann Institute of Science, Rehovot, Israel 7610001

${ }^{2}$ Berlin Institute of Medical Systems Biology and Systems Biology, Max Delbruck Center for Molecular

Medicine, Berlin, Germany

${ }^{3}$ Department of Anatomy \& Structural Biology, Albert Einstein College of Medicine, Bronx, NY, USA

${ }^{4}$ Corresponding authors:

JEG: jeffrey.gerst@weizmann.ac.il; Tel: +972-8-9342106; Fax +972-8-9344108

GH: gal.haimovich@weizmann.ac.il; Tel: +972-8-9344428

Keywords: smFISH, RNA-Seq, RNA transfer, RNA trafficking, tunneling nanotubes 


\section{Summary}

Full-length mRNAs can transfer between adjacent mammalian cells via direct cell-to-cell connections called tunneling nanotubes (TNTs). However, the extent of mRNA transfer at the transcriptome-wide level (the transferome) is unknown. Here, we analyzed whole transcriptome mRNA transfer between heterogeneous human-mouse cell populations in in vitro co-culture using RNA-sequencing. Our data indicate that mRNA transfer is non-selective, prevalent across the human transcriptome, and that the amount of transfer to mouse embryonic fibroblasts (MEFs) strongly correlates with the endogenous level of gene expression in donor human breast cancer cells (MCF7). These results were validated by both quantitative RT-PCR and in situ hybridization, and analysis shows that typically $<1 \%$ of endogenous mRNAs and IncRNAs undergo transfer. Nonselective expression-dependent RNA transfer was further validated using synthetic RNA reporters. Notably, significant differential changes in the native MEF transcriptome were observed in response to co-culture, including the upregulation of multiple cancer- and cancer-associated fibroblast-related genes and pathways. Together, these results lead us to suggest that TNTmediated RNA transfer could be a phenomenon of physiological importance under both normal and pathogenic conditions. 


\section{Introduction}

RNA molecules can act as mediators of intercellular communication in plants and animals during normal growth and development, as well as different pathologies such as viral infections or cancer (Dreux et al., 2012; Haimovich et al., 2021; Lu et al., 2019; O'Brien et al., 2020; Ramachandran and Palanisamy, 2012; Valadi et al., 2007). Although initial evidence of the intercellular transfer of RNA was found in the early 1970s (Kolodny, 1971; Kolodny, 1972), the mechanism of transfer gained attention much later.

The prevalent mechanism by which RNAs are thought to be transferred is through extracellular vesicles (EVs), which include apoptotic bodies, microvesicles and exosomes. Best studied are exosomes, which are vesicles of endocytic origin with sizes ranging from 40-100 nm and can transfer information in the form of proteins, lipids, DNA and RNA (O'Brien et al., 2020). Released by numerous cell types (e.g. immune cells, neuronal and cancer cells) (Mittelbrunn et al., 2011; Villarroya-Beltri et al., 2013), they are secreted into extracellular media and body fluids (e.g. saliva, blood plasma, breast milk and urine) (Zhang et al., 2019b). Profiling of their RNA content using DNA microarrays or RNA sequencing has revealed that while multiple species of RNAs are present in exosomes (e.g. snoRNA, siRNA, Y-RNA, IncRNA, and vault RNA), work has mainly focused on microRNAs (miRs) (Li et al., 2014; Valadi et al., 2007). Exosomes have also been suggested to transfer mRNA (or at least fragments of mRNA). One report found that GFP mRNA in exosomes was taken up by a colon cancer cell line and translated (Jiang et al., 2015). However, exosomes may not be the sole agent by which RNAs transfer from one cell to another. In fact, multiple studies show that only small sized RNAs (e.g. miRs) and fragments of mRNA are likely to be enriched in the exosomes (Batagov and Kurochkin, 2013; Perez-Boza et al., 2018; Zhang et al., 2018). Thus, exosomes may not be the preferred mode of full-length mRNA transport between cells. Interestingly, ARC and PEG10 mRNAs encode proteins that can form retroviral-like capsids and package their own mRNAs for transfer to neighboring cells (Ashley et al., 2018; Pastuzyn et al., 2018; Segel et al., 2021). However, this form of transfer is probably limited to a small set of mRNAs encoding retroviral-like capsid proteins.

Our lab has shown that full-length messenger RNA (mRNA) molecules can transfer between mammalian cells, but do so via tunneling nanotubes (TNTs) (Haimovich et al., 2017; Haimovich and 
Gerst, 2019). TNTs are cytoplasmic connections extending between cells that are thinner and longer than other dynamic cellular protrusions, such as lamellipodia and filopodia (Cordero Cervantes and Zurzolo, 2021). TNTs have been shown to differ significantly from filopodia in both actin architecture and overall structure (Korenkova et al., 2020; Ljubojevic et al., 2021; SartoriRupp et al., 2019). TNTs, which are typically 0.2-1 $\mu \mathrm{m}$ in diameter and up to $>150 \mu \mathrm{m}$ long, were shown to transfer organelles (Goodman et al., 2019; Kolba et al., 2019; Murray and Krasnodembskaya, 2019; Wang et al., 2011; Zou et al., 2020), bacteria (Kim et al., 2019; Onfelt et al., 2006), viruses (Eugenin et al., 2009; Guo et al., 2016; Panasiuk et al., 2018; Roberts et al., 2015; Tiwari et al., 2021), proteins (Biran et al., 2015), and microRNAs (Lu et al., 2019; Valadi et al., 2007). TNTs have been reported to be involved in a multitude of biological processes, such as stem cell differentiation, immune response, and neurodegenerative diseases, among others (Abounit et al., 2016; Reichert et al., 2016; Zhu et al., 2021). TNT-mediated RNA transfer has been demonstrated in only a few physiological contexts [reviewed in (Haimovich et al., 2021)]. In addition to our work (Haimovich et al., 2017; Haimovich and Gerst, 2019), published RNA-sequencing data and qPCR analysis were used to detect exosome-independent transfer of keratinocyte-specific mRNAs to Langerhans cells (Su and Igyarto, 2019), and GFP and GNAT1 mRNAs were shown to transfer in vivo in a photoreceptor transplantation model (Ortin-Martinez et al., 2021).

Previously, we used a simple 2D co-culture model of donor and acceptor cells along with single molecule fluorescent in situ hybridization (smFISH) to quantitatively study TNT-mediated mRNA transfer (Haimovich et al., 2017; Haimovich and Gerst, 2019). Using this approach, we found that several full-length endogenous or ectopically expressed mRNAs undergo intercellular transfer between a variety of cell types, including immortalized cells, primary cells, and even human-mouse cell co-cultures. While the level of transfer was often $<1 \%$ of the endogenously expressed message in donor cells, the most abundantly transferred mRNA was that of $\beta$-actin mRNA, which transferred at a level of up to $5 \%$ in some experiments. Initial analyses showed that transfer is influenced by the expression level of the RNA in donor cells and by stress conditions. We further found that the transfer of mRNAs is inhibited by both cytoskeletal and small GTPase inhibitors, as well as by the binding of multiple MS2 coat proteins (MCPs) to a 24xMS2 stem-loop aptamer sequence in the mRNA (Haimovich et al., 2017). Inhibition by the MS2 system could be explained by extensive MCP 
binding and hindrance to transfer or by interference with a yet-to-be-identified protein that may coat the transferred mRNA (Haimovich and Gerst, 2019).

Here we used human MCF7 breast cancer cell-line and immortalized mouse embryo fibroblast (MEF) cells grown in co-culture to define the extent of the RNA transferome and the effect of co-culture upon the native transcriptome in vitro. By employing deep sequencing we found that nearly all mRNAs transfer and in a manner that strongly correlates with the donor cell expression level. Moreover, by increasing gene expression using reporter RNAs we could verify that increased expression results in increased transfer. Similar to our previous findings (Haimovich et al., 2017), the overall level of transfer was found to be $<1 \%$ of the expression level in the donor cells and was dependent upon cell-cell contact. To explore the mechanism of mRNA transfer, we used two approaches aimed at identifying cis RNA elements that might be required. First, we searched for unique elements present in transferred RNAs using bioinformatics and second, we fused short segments of $\beta$-actin mRNA to a reporter mRNA to test if they were able to increase transfer. However, neither approach revealed the presence of an element that enhances RNA transfer, indicating that the process is inherently non-selective. Lastly, we detected significant differential changes in the native transcriptome of the MEF cells in response to co-culture with MCF7 cells, including the upregulation of multiple cancer- and cancer-associated fibroblast (CAF)related genes and pathways. Together, these results lead us to suggest TNT-mediated RNA transfer could be a phenomenon of physiological importance under both normal and pathogenic conditions. 


\section{Results}

\section{An antigen-based cell sorting method to separate human and mouse cells after co-culture}

In order to study genome-wide RNA transfer, it is essential to separate the two cell types after coculture and prior to RNA extraction and downstream analysis (schematic shown in Figure 1A). We previously demonstrated using smFISH that up to $2 \%$ of $\beta$-actin mRNA (e.g. $~ 30$ copies/cell) can undergo transfer from MEFs to human MCF7 cells within $12 \mathrm{hrs}$ of co-culture (Dasgupta and Gerst, 2020). As in that study, here we used mouse MEFs tagged with 24 repeats of the MS2 coat protein (MCP)-binding sequence (MBS) between the ORF and $3^{\prime}$ UTR of both endogenous alleles of $\beta$-actin (referred to hereafter as "MBS-MEFs") (Haimovich and Gerst, 2019; Lionnet et al., 2011) and human MCF7 cells. MCF7 cells specifically express a cell surface molecule, CD326 or Epithelial Cell Adhesion Molecule (EpCAM). Thus, we employed magnetic beads conjugated to anti-CD326 antibodies in order to separate heterologous cell populations of MBS-MEF and MCF7 cells to a high degree of purity. It is critical to have complete cell separation ( $100 \%)$, since even a small contamination (e.g. $0.1-0.3 \%$ ) of donor cells in the isolated acceptor cells can lead to a high background relative to the transferred RNA signal, particularly when the level of RNA transfer is expected to be low. To eliminate background signals originating from incomplete cell separation, we compared our co-culture samples to MEFs and MCF7 single cultures that were grown separately, harvested, mixed after cell harvest, and immediately separated (referred to hereafter as the "Mix"). Once separated, we checked the efficiency of cell sorting from the Co-culture, Mix, and Single cell culture samples by flow cytometry. Based on the purity of human and mouse cell fractions, as determined by flow cytometry (Figure 1B and Supplementary Figure 1A), we found that the mouse MEF-enriched fractions were much better sorted, as compared to the human MCF7 cell-enriched fractions (Table 1).

Next, total RNA from the sorted cell populations was sequenced to identify the transferred RNAs, as well as to measure the native transcriptomes from single cell cultures. We first considered how to treat the raw reads with respect to the length and type of fragment (e.g. single or pairedends) to obtain the best results (Supplementary Figure 1B). Due to regions with a high degree of homology between the human and mouse transcriptomes, using sub-optimal length reads may lead to the mapping of human reads to the mouse genome and vice versa. Based on a previous in 
silico simulation of mapping 25, 50, 75 and $100 \mathrm{bp}$ long single- and paired-end reads from the human transcriptome to the mouse transcriptome, we observed that short (25 bp), single-end reads have a very high (>85\%) non-specific alignment with the mouse genome, which was drastically reduced by using longer (>100 bp) and paired-end reads (Dasgupta and Gerst, 2020). We also noted that using suboptimal sequencing depth (i.e. $<25$ million reads per sample) can lead to missing rare transcripts (data not shown). Hence, we chose to sequence the samples to obtain maximal depth (e.g. $\geq 100$ million reads per sample) and using 2x150 base-pair paired-end reads. We obtained between 94 to 281 million reads per sample at an average of 168 million paired-end reads per sample (Supplementary Data File 1 - Table 1). Between 90-92\% of the reads were uniquely aligned to the respective reference genomes, which is an indicative of the high quality of library preparation and it was either at par or better than typical unique alignment rates (Mortazavi et al., 2008; Sarantopoulou et al., 2019; Sun et al., 2013; Zhao et al., 2015). More than 14,000 mouse and 16,000 human genes were annotated to their respective RefSeq database. Such high depths of sequencing ensure that low levels of mRNA transfer could be detected.

Initial analysis of mouse-derived RNA in the human transcriptome revealed that more mouse RNA was present in MCF7 cells obtained from the Mix than from MCF7 cells in Co-culture (the percentage of unique mouse-aligned reads in the Mix samples was actually greater than that of the Co-culture; Supplementary Data File 1-Table 1). This result is probably due to the high level of MBS-MEF contamination (e.g. 0.17-0.27\%) in the Mix samples (Figure 1B and Table 1). In contrast, the level of human MCF7 cell contamination in the MEF fraction was very low (e.g. $\leq 0.05 \%$ ) and was comparable between the Co-culture and Mix samples. Moreover, the percentage of unique human-aligned reads in Co-culture samples (versus the Mix samples) was substantially greater (e.g. $\sim 1.6 \%$ versus $1.1 \%$, respectively (Supplementary Data File 1 - Table 1). Thus, we decided to focus only on human RNAs present in the mouse-derived transcriptome samples (i.e. human-to-mouse RNA transfer). In total, 10,566 transcripts of human genes were detected in Coculture-derived or Mix-derived mouse-enriched samples (Figure 2A; Supplementary File 1 - Table 2). Of those, 7,504 genes had RPM counts of more than 10 in both co-culture replicates (Supplementary Data File 1 - Table 2), of which 7501 genes had a fold-change (FC) of $>1$ (i.e. more reads in the Co-culture vs Mix), and 6827 genes had FC of $\geq 2$ (Supplementary File 1 - Table 2). As a 
positive control for the experiment, we first confirmed the transfer of human $\beta$-actin mRNA by both RT-PCR and qRT-PCR of the mouse-derived RNA using human $\beta$-actin-specific oligos (Figures $1 C$ and $D$, respectively). Both detection methods revealed a significant enrichment of human $\beta$ actin $\mathrm{mRNA}$ in the MBS-MEFs after co-culture.

\section{The human transferome encompasses the major fraction of the transcriptome}

Whole transcriptome profiling of the human- and mouse-enriched samples from Co-culture and control (Mix) samples revealed the robust presence of human-specific reads in the mouse samples (Figure 2A). Principal Component Analysis of these samples indicated that Co-culture samples have a similar profile of human-aligned genes and were different from control Mix and Single culture samples, as expected (Figure 2B). The number of cross-species reads is expected to be higher in Co-culture samples (due to the transfer of RNAs) than Mix samples (assuming the number of residual cells after sorting is similar). Comparison of the results from two biological replicates of Co-culture, Mix and Single culture samples revealed that most transcripts of human genes are able to transfer to varying degrees (Figure 2A; Supplementary Data File 1 - Table 2).

As RNAs from most human genes are transferred, the distribution of these RNAs in the mouse cells is globally shifted to the right, i.e. the average number of reads per human gene in mouse samples is much higher in Co-culture samples as compared to the Mix samples $(p=0.0001$ for all genes; Figure 2C). By employing a single-tailed unpaired $t$-test, we found that 283 mRNAs robustly transferred from human (MCF7) cells to mouse (MBS-MEF) cells with a fold-change of more than 2 (Figure 2D, Supplementary Data File 1 - Table 3). Many of the identified mRNAs included cytoskeletal components (ACTB, ACTG), translation factors (EEF1A1, EEF2), ribosomal proteins (RPL8, RPL4, RPL7) and other "housekeeping" genes (GAPDH, PABPC1). Among this group we also identified mRNAs encoding multiple types of keratins (e.g. KRT8, 18, 19, and 80), similar to those reported to transfer from keratinocytes to epidermal-resident Langerhan cells (Su and Igyarto, 2019). It should be noted that this statistical test is underpowered due to the low number of replicates and, hence, likely underestimates the number of mRNAs undergoing robust transfer. Essentially, these 283 genes represent the most abundantly transferred mRNAs in terms of absolute number. We note that amongst the 7 endogenously expressed mRNAs previously shown 
by us to transfer (Haimovich et al., 2017), only ACTB and CCND1 underwent robust transfer. This may also be due to the lower endogenous expression levels of these genes [e.g. BRCA1 (3252 RPM), HER2/ERBB2 (25690 RPM), MITF (436 RPM), MT2A (4383 RPM) and SERP2 (undetected)] in MCF7 cells in comparison to CCND1 (108670 RPM) or ACTB (320214 RPM) (Supplementary File 1 Table 4). Indeed, BRCA1 and ERBB2 gene expression levels in MCF7 cells are respectively 1.5-fold and $\sim 45$-fold lower than in the HEK293 and SKBR3 cells (Human Protein Atlas) (Uhlén et al., 2015) in which we already observed low levels of transfer (Haimovich et al., 2017). This further implies that low gene expression can affect the detection of transfer of these mRNAs by RNA-seq.

Since the 283 abundantly transferred mRNAs were endogenously expressed at high levels in MCF7 cells, we wondered if transfer is dependent upon the level of expression. To determine if the level of mRNA transfer correlates with endogenous RNA expression in donor cells, we performed linear regression analysis of the human reads found in Co-culture samples with those of the Mix (Figure 2E) and in human Single cultures (Figure 2F). Human reads from the MEFenriched fraction of the "Mix" sample can be attributed to the residual presence of MCF7 cells after magnetic bead sorting, whereas those in MCF7 single cultures are representative of the initial mRNA expression levels prior to co-culture. We found that the number of transferred human RNAs strongly correlated with their expression levels (Pearson and Spearman coefficients $>0.9$ ) (Figure $2 \mathrm{~F})$, most falling within the $99 \%$ confidence interval of the regression. This indicates that the level of gene expression prior to co-culture can be a dominant predictor of RNA transfer. A similar correlation is also seen between the level of transferred human RNAs and their endogenous expression in MCF7 cells after co-culture (Figure 2G). This is in agreement with our previous observation, which showed that the transfer of MS2-tagged human Cyclin D1 (CCND1-MBS) mRNA from HEK293 cells to MEFs is enhanced upon increased gene expression in the donor cells (i.e. using a stronger promoter). Likewise a strong correlation was observed between ACTB-MBS expression levels and ACTB-MBS mRNA transfer when comparing between immortalized and primary donor MBS-MEFs (Haimovich et al., 2017).

Next, we looked at the relationship between the endogenous expression in the donor MCF7 cells and the fold-change (FC) of transfer (i.e. the fold increase of RPM counts in Coculture samples divided by the Mix samples). When looking at the whole transcriptome, we found no 
correlation between endogenous RNA expression in donor cells to the $\log _{2} \mathrm{FC}$ of human RNAs in co-cultured cells (Supplementary Figure 2, Pearson coefficient $=0.07$ ). We noted that unlike the 283 robustly expressed and transferred RNAs described above, mitochondria-encoded RNAs (e.g. 13 mRNAs and 2 rRNAs) showed poor transfer ( $\left.\log _{2} \mathrm{FC}=0.03-0.45\right)$ despite their high expression. This result further strengthens our confidence that we measure actual RNA transfer and not contamination. Most of the genes with $\log _{2} \mathrm{FC}<0$ (i.e. presumably RNAs that do not transfer) and $\log _{2} \mathrm{FC}>3$ (i.e. presumably highly transferred RNAs) have values of less than 10 RPM (Supplementary File 1 - Table 4). Thus, we cannot determine if these $\log _{2} \mathrm{FC}$ values are accurate or artifacts relating to the low number of reads.

We further observed that the median percentage of transfer for all human RNAs was low [0.34\%, $\log _{10}$ (percentage of transfer) = -0.44] (Figure 3A, Supplementary Data File 1 - Table 4). Although the absolute number of transferred RNAs (using RPM as a measure) depended on gene expression level in the donor cells, the percentage of RNA transfer did not correlate linearly with gene expression (Figure 3B, Supplementary Data File 1 - Table 4). This result indicates that only a low proportion of RNAs from the mammalian transcriptome is likely to undergo transfer to neighboring cells. Next, we examined whether the percentage transfer of mRNA correlates with mRNA stability. To check this, we compared the percent transfer data with a recently published genome-wide analysis of half-lives of mRNAs in K562 cells (Blumberg et al., 2021). In total, 4972 genes were correctly annotated between the two datasets. We found that the percentage of transfer of the total RNA population, as well as that of the group of 283 robustly transferred mRNAs, was largely independent of mRNA stability (Figure 3C, Supplementary Data File 1 - Table 5). Interestingly, we could also detect the transfer of mRNAs from 12 primate-specific genes (e.g. DHRS4L2, GTF2H2C, NBPF10, NBPF14, ALG1L, CBWD2, APOL2, ZNF43, ZNF726, ZNF816, ZNF680, and ZNF718) in co-cultured MEFs. These genes are highly expressed in cortical regions of primate brains and are not reported to have any mouse orthologues (Florio et al., 2018). The endogenous expression of most of these genes in MCF7 cells was found to be low, as was the level of transfer (Supplementary Data File 1 - Table 6).

We also examined the RNA-seq data for the presence of long non-coding RNAs (IncRNAs). We detected the expression of 174 IncRNAs in MCF7 Single cultures (out of 5301 known IncRNAs) 
and identified 102 having >10 RPM in Coculture samples - 100 of which were transferred with a FC $>2$ (Supplementary Data File 1 - Table 7). We noted that 5 IncRNAs were among the most highly endogenously expressed genes in MCF7 cells and amongst the 283 robustly transferred RNAs (Supplementary Data File 1 - Table 3).

Since the donor human cell line (MCF7) was derived from breast cancer tissue, we wondered if the mRNAs of human genes known to drive cancer undergo transfer to neighboring acceptor fibroblasts (MBS-MEFs). To check this, we compared a list of 7500 genes with RPM counts of $\geq 10$ in both replicates of Co-culture samples and having a fold-change $>1$ with a list of 72 genes previously shown to be overexpressed in breast cancer and 93 genes found with somatic mutations in breast cancer samples (Axelsen et al., 2007; Nik-Zainal et al., 2016). We found that mRNAs corresponding to 40 breast cancer-related overexpressed genes and 77 breast cancer-related mutated genes underwent transfer from MCF7 to MBS-MEF cells ( $p=0.074$ and $p<3.776 e-13$, respectively, using a hypergeometric test) (Figure 3D; Supplementary Data File 1 - Table 8). One gene (BUB1B) was found to be both overexpressed and mutated, and to undergo transfer.

We validated the results from RNA-Seq of 10 highly transferred genes (out of the set of 283 genes mentioned above; Figure 2D) by qRT-PCR in two independent experiments. We also examined the transfer of four poorly transferred genes as negative controls, and $\beta$-actin as a positive control. In full agreement with the RNA-seq results (Figure 2), the robust transfer of RNAs shown by sequencing could also be verified using qRT-PCR (Figure 4A). In parallel, we validated the transfer of a set of highly transferred mRNAs using smFISH for three genes (e.g. KRT8, PSAP and CCND1) in MBS-MEF cells using human-specific FISH probes (Figure 4B and C). In agreement with the RNA-seq and qRT-PCR data, we could detect robust transfer of these three genes from human MCF7 cells to mouse MBS-MEF cells (Figure 4C). As expected, the transfer of KRT8 mRNA was noticeably higher than that of CCND1 or PSAP, which might be attributed to the higher expression of KRT8 in MCF7 cells. Thus, we could verify intercellular RNA transfer using three different approaches. 


\section{mRNAs encoding translation-related proteins dominate the human transferome}

To check if the transferred mRNAs are associated with specific Gene Ontology terms, we analyzed the list of highly transferred mRNAs by DAVID (Database for Annotation, Visualization and Integrated Discovery) and GeneCards for the GO terms that were highly enriched (Huang da et al., 2009a; Huang da et al., 2009b; Stelzer et al., 2016). We found that most of the mRNAs were involved in translation initiation, RNA transport, ribosome biogenesis and mRNA splicing (Supplementary Figure 3, Supplementary Data File 2). In terms of molecular functions, transferred mRNAs encoded for poly-A binding proteins, ribosomal proteins and translation factors and localizing to the cytosol, cell membrane or ribosome (Supplementary Figure 3, Supplementary Data File 2). We also looked for pathway enrichment using KEGG (Kyoto Encyclopedia of Genes and Genomes) and Reactome databases (Fabregat et al., 2018; Fabregat et al., 2017; Kanehisa and Goto, 2000; Wu and Haw, 2017). The transferred mRNAs were enriched for pathways such as RNA transport, metabolism, translation and rRNA processing (Supplementary Figure 3, Supplementary Data File 2). Since the genes encoding these cellular functions tend to be highly expressed, it might be expected that they would be the most abundantly transferred RNAs.

\section{Level of intercellular RNA transfer depends upon gene expression}

To validate the hypothesis that gene expression is an important determinant of mRNA transfer, we employed two approaches. In the first approach, we co-cultured wild-type (WT) MEF cells with MBS-MEF donor cells expressing either high or low levels of an exogenous mRNA encoding tdTomato that was stably expressed under the control of a constitutive promoter (Figure 5A and B). tdTomato-low expression cells were found to express an average 429 molecules of tdTomato mRNAs, out of which, an average of 7 molecules ( 1.6\%) were transferred to WT-MEF acceptor cells (Figure 5B). On the other hand, tdTomato-high expression cells were found to express an average of 1250 molecules of tdTomato mRNA, of which 25 molecules (2\%) were able to transfer (Figure 5B).

In a second approach, we co-cultured WT-MEFs with donor MBS-MEFs expressing tdTomato mRNA under the control of a Doxycycline-inducible promoter in the presence of increasing concentrations of Doxycycline (Figure 5C). Higher concentrations of Doxycycline (4 
$\mu \mathrm{g} / \mathrm{ml}$ ) induced a higher level of tdTomato mRNA expression (average $=492$ copies/cell) and, consequently, transferred more mRNA to the acceptor cells (average: 1.5 copies/cell) than lower levels of Doxycycline ( $2 \mu \mathrm{g} / \mathrm{ml}$; average expression = 165 copies per cell; $<1$ transferred) (Figure 5C). Together, these results provide strong evidence of the role of gene expression in mediating mRNA transfer and in a promoter-dependent manner.

\section{Intercellular mRNA transfer does not appear to necessitate RNA motifs}

We next examined if there are any sequence motifs involved in RNA transfer. We adopted both experimental and bioinformatic approaches to examine the sequences for transfer-promoting motifs encoded either in the coding sequences or in the UTRs of RNA transferred RNAs.

To identify such an element by experimental means, we used $\beta$-actin mRNA - one of the most abundantly transferred mRNAs - as a model for RNA transfer. We reasoned that if there was a transfer-promoting element, it could enhance transfer of a reporter mRNA. We divided the coding sequence (CDS) of $\beta$-actin mRNA into three overlapping segments (CD1, CD2 and CD3) and the 3'UTR into two non-overlapping segments (3U1 and 3U2) (Supplementary Figure 4A). Each fragment was cloned downstream of the stop codon of the tdTomato reporter and the mRNA was stably expressed from a constitutive ubiquitin promoter in MBS-MEFs (Supplementary Figure 4A). tdTomato alone was used as a baseline for transfer efficiency without any $\beta$-actin fragment. Transfer of the various tdTomato- $\beta$-actin constructs from MBS-MEFs to WT-MEFs in co-culture was examined by smFISH using tdTomato-specific probes (Supplementary Figure 4B). We found that donor MBS-MEFs expressing either tdTomato alone or fused with $\beta$-actin gene fragments expressed the RNAs at similar levels (Supplementary Figure 4C). Next, we examined RNA transfer (Supplementary Figure 4D) and found that tdTomato mRNA alone transferred at a higher level than that of the fusion constructs, although the fusions amongst themselves showed similar levels of transfer. Thus, we could not identify a fragment of $\beta$-actin that promotes mRNA transfer, at least in the context of this assay, i.e. placed in the 3'UTR of tdTomato and expressed ectopically.

Next, we analyzed the 5'UTR, 3'UTR, and CDS RNA and encoded amino acid sequences of the 280 most highly transferred mRNAs by MEME Suite (Bailey et al., 2009) to look for consensus motifs that might be connected to transfer (Supplementary Figure 5). While no such motif was 
detected at the level of amino acid sequences or in the UTRs, three different purine-rich motifs were enriched in the coding sequences of nearly all mRNAs (Supplementary Figure 5A). Two contain the sequence 5'-GAAGAAG-3', which is similar to the 5'-GCAGAAG-3' or 5'-GGAGAAG-3' sequences present in each of the coding sequence fragments of $\beta$-actin, described above, but did not show enhanced transfer (Supplementary Figure 4D).

To determine whether these motifs might be connected to promoting RNA transfer, we examined for the presence of motifs in genes exhibiting a low level of RNA transfer. We selected three separate sets of genes of similar number as that of the highly transferred genes (i.e. between 220-300 genes) and looked for consensus sequences in the coding regions (Supplementary Figure 5B). Interestingly, all three sets contained similar purine-rich sequences as found in the highly transferred genes, with the 5'-GAAGAAG-3' motif identifiable in Sets 2 and 3 (Supplementary Figure 5B). As this sequence is not specific to highly transferred genes it is unlikely to be a transferpromoting feature. Thus, neither of the two approaches could conclusively identify elements that might promote RNA selection for transfer.

\section{Intercellular mRNA transfer depends on direct cell-to-cell contact}

Multiple studies have reported the presence of RNAs in extracellular vesicles, such as exosomes and exosome-like vesicles (Ekstrom et al., 2012; Matsuno et al., 2019; Valadi et al., 2007). More importantly, breast carcinoma cell lines such as the MCF7 cells used in this study have been shown to release exosomes and other EVs that can package RNAs and influence the physiology of acceptor cells (Jafari et al., 2020; Lau and Wong, 2012). In contrast to EV-mediated transfer, however, we demonstrated that mRNAs transfer via TNTs that confer direct cell-cell contact, and not by diffusion through the media(Haimovich et al., 2017; Haimovich and Gerst, 2019). The transfer of both $\beta$-actin and GFP mRNAs was completely abrogated when donor and acceptor cells were separated in space (e.g. using a tripod/transwell setup) or when the acceptor cells were treated with donor cell-derived conditioned medium (Haimovich et al., 2017). Thus, we asked whether the human mRNAs detected in mouse acceptor cells were contributed by a contactdependent mechanism (e.g. TNTs) or via contact-independent pathways (e.g. EVs). To test this, we co-cultured MCF7 donor cells and MBS-MEF acceptor cells on same plate or physically separated 
several millimeters apart using a quadrapod plate setup (see Methods and Materials). Alternatively, we treated the MBS-MEF cells with conditioned medium derived from a MCF7 single culture (Supplementary Figure 6A). We then separated the cells and extracted RNA as described above and followed the transfer of select mRNAs by qRT-PCR. We chose four genes from the list of highly transferred genes identified by RNA-sequencing (e.g. ACTG, GAPDH, TRIM37, and KRT8), while using ACTB as a positive (TNT-dependent) control for the analysis. The transfer of mRNAs was found to be highest in the Co-culture samples as compared to the quadrapod or conditioned media-treated samples across two independent replicates (Supplementary Figure 6B). This indicates that the mRNAs did not transfer by diffusion (e.g. either by secreted vesicles or ribonucleoprotein complexes), but requires cell-cell contact. As the genes selected for this experiment encode diverse biological functions and do not belong to any common pathway, it suggests that contact-dependent transfer is likely to be the predominant mechanism for transcriptome-wide mRNA transfer.

\section{Co-culture with human cells leads to differential changes in the mouse transcriptome}

Next, we were curious to check the impact of co-culture conditions on acceptor cells. RNA-seq analysis revealed that the mouse transcriptome in Co-culture samples was significantly different from that of the Mix and Single cultures, which cluster together and have very similar transcriptomic profiles (Figure 6A and B). This indicates that MBS-MEFs undergo stark changes in gene expression upon co-culture with MCF7 cells. We detected more than 4000 genes that are $\geq 2$ fold differentially expressed, including 1000 upregulated genes and $\sim 3000$ downregulated genes (Figure 6C) (Supplementary Data File 1 - Table 9). Interestingly, we observed the 3.5-fold upregulation of a cancer-associated fibroblast (CAF) marker, Tenascin-C (TNC) (Ni et al., 2017), in the MEF-enriched fraction of the Co-culture sample (Supplementary Data File 1 - Table 9). This raises the speculation that MEFs might become CAF-like when co-cultured with a cancer cell line (e.g. MCF7 cells). To explore this further, we compared the fold-change of differentially regulated genes from MEFs grown in Co-culture (versus those from the Mix) with the corresponding genes in CAFs (versus their precursor mesenchymal stem cells - MSCs), as reported in a recent study (Yu et al., 2020). Interestingly, we found 30 upregulated and 17 downregulated genes conserved 
between the two datasets (Figure 7A, Supplementary Data File 1 - Table 10). Among upregulated genes in the MEFs, multiple extracellular-matrix associated genes (e.g. ACTA1, ACTA2, COL6A3, ADAM12, ADAM19) were also upregulated in CAFs associated with metastatic lung cancer (Figure 7B). Furthermore, mouse KRT8, which is frequently associated with apical CAFs (apCAFs) in the breast and pancreatic cancer microenvironment (Elyada et al., 2019; Sebastian et al., 2020) was upregulated in MEFs in response to co-culture with MCF7 cells (Supplementary Data File 1 - Table 9). This indicates that co-culture with human cancer cells might lead to CAF-like phenotypes in cultured fibroblasts.

We analyzed the differentially expressed mouse genes for upregulated and downregulated pathways using KEGG. Top upregulated pathways included "Ribosome biogenesis in eukaryotes", "RNA transport" and "Focal adhesion", while top downregulated pathways included signaling pathways, such as "Calcium Signaling pathway" and "Rap1 signaling pathway" (Supplementary Figure 7, Supplementary Data File 3). Upon close observation, many cancer-related pathways (e.g. MAPK signaling, Ras signaling) were found to be upregulated, while pathways such as cytokinecytokine interactions and transcriptional misregulation in cancer were downregulated (Figure 6C). Another major cancer-related pathway, "ECM-Receptor interaction" was found to be both up- and - downregulated in MBS-MEFs in response to co-culture with MCF7 cells (Figure 6C), with most of the upregulated genes associated with poly-A RNA binding, translation initiation, ribosome biogenesis and ribosome assembly-related GO terms (Supplementary Figure 7). Interestingly, cell immunity -related genes were significantly downregulated, leading to speculation that RNA transfer and/or co-culture modulates the immune response of acceptor cells (Supplementary Figure 7D). 


\section{Discussion}

In this study, we employed a genome-wide transcriptomic-based approach to understand the global prevalence of intercellular mRNA transfer. Using a human-murine co-culture system, we developed a simple, comprehensive, and quantitative method to study RNA transfer that involves co-culturing heterologous cell populations, sorting them by antigen-based affinity purification, and performing deep sequencing (Figure 1A). We found that numerous RNAs undergo transfer (Figure 2A and Supplementary Data File 1 - Tables 1 and 2) and that the number of transferred mRNAs strongly correlates linearly with the endogenous expression level in donor cells (Figure 2F-G), which in turn, led to the discovery that most abundantly transferred RNAs are highly expressed genes such as $\beta$ - and $\gamma$-actin, cytoskeletal components, translation factors, ribosomal subunits and other genes (Figure 2D). We found that the level of gene expression alone explains more than $90 \%$ of RNA transfer (Figures 2E-G and 5). This is in agreement with our previous finding that transfer of human Cyclin D1 mRNA and mouse $\beta$-actin mRNA correlates with the expression level in donor cells (Haimovich et al., 2017). Another study, that reported transfer of keratinocyte-associated mRNAs to Langerhans cells, mostly through a contact-dependent mechanism, also found that the amount of transferred RNAs (as quantified by PCR) positively correlated with gene expression (Su and Igyarto, 2019).

Similar results have also been reported in plants, where the long-distance transport of mRNAs between non-contiguous cells is achieved via plasmodesmata and sieve elements that play a major role in development. An analysis of mRNAs exhibiting long-distance transport in Arabidopsis showed that was largely non-selective and dependent on gene expression (Calderwood et al., 2016; Hofmann, 2016). In case of RNA transfer between species, such as hostparasitic plants, a large proportion of host and parasite mRNAs were found in each other's tissues in an expression-dependent manner (Notaguchi et al., 2015). In an instance of cross-species grafting, no specific cis motif was found among Arabidopsis mRNAs that were found in Nicotiana tissues (Notaguchi et al., 2015). However, a recent report found that RNA modification [5-methyl cytosine $\left.\left(m^{5} \mathrm{C}\right)\right]$ mainly in the proximal end of coding regions was responsible for transport of certain mRNAs from shoot to root of Arabidopsis (Yang et al., 2019). In addition, two works 
describe a tRNA-like structure or actual bi-cistronic mRNA-tRNA transcript that acts as a cis-acting element in plant mRNA transfer (Huang and Yu, 2009; Zhang et al., 2016).

We did not detect any gene with a disproportionally high level of transfer with respect to endogenous expression (Figure 2D-G), indicating that the presence of other transfer promoting factors (e.g. RNA motifs; Supplementary Figures 4 and 5) beyond gene expression is unlikely. On the other hand, we showed previously that the level of mRNA transfer could depend on cell type, as HER2 mRNA transfer from two human cell lines (e.g. NCl-N87 and SKBR3 cells) to MEFs was similar, although the expression level in SKBR3 cells was 2-fold higher (Haimovich et al., 2017). Thus, RNA transfer might correlate with endogenous expression levels within the same cell type, but not necessarily across different cell types. The existence of transfer-inhibiting or -promoting elements recognized by cell-type specific factors could provide a possible explanation why some cell types transfer certain mRNAs or IncRNAs better or worse than others, even when taking gene expression levels and growth conditions (e.g. stress conditions or presence of extracellular matrix proteins, like fibronectin) into consideration. These hypotheses should be further explored, since cell type-derived differences in RNA transfer efficiency could have different physiological outcomes.

Interestingly, a report characterizing the EV transcriptome of hepatic cancer cell lines identified 238 protein-coding mRNAs, many of which were found to be highly transferred here as well. These included genes encoding ribosomal proteins, ACTG, ACTB, and EEF2, etc. This implies that these RNAs might also be transferred by EVs and that the loading of RNAs into such vesicles may be expression-dependent (Berardocco et al., 2017). However, in this study and in our previous work (Haimovich et al., 2017) we could not detect diffusion-based mRNA transfer. In contrast, we now provide strong evidence that transfer is due to contact-dependent mechanisms (e.g. TNTs) (Supplementary Figure 6).

Besides expression dependence, another hallmark of intercellular RNA transfer is the relatively low level of transfer (e.g. average of $<1 \%$ of endogenous gene expression; Figure $3 \mathrm{~A}$ ). This makes transfer difficult to detect by bulk RNA sequencing and even more so by single-cell RNA sequencing (scRNA-seq). scRNA-Seq platforms, such as DropSeq, have a low level of accuracy and the sensitivity drops further when analyzing low expressed genes (e.g. $<50$ copies of mRNA per 
cell) (Torre et al., 2018). In addition, data from scRNA-seq using low amounts of input RNA is noisy and, thus, is less reliable (Brennecke et al., 2013). In an attempt to detect transferred RNAs from MCF7 to MBS-MEFs using a newly described scRNA-Seq process, BAG-Seq (Li et al., 2020), only 2000 genes were identified, yet none of which (not even $\beta$-actin) could be detected as having undergone transfer (data not shown). Further improvements in scRNA-seq technology, in terms of sensitivity, might go far towards allowing exploration of this phenomenon especially in tissues. Alternatively, multiplex FISH approaches (e.g. MERFISH or seqFISH+ (Eng et al., 2019; Xia et al., 2019)) might prove superior to scRNA-seq due to higher sensitivity. In fact, our smFISH results (Figure 4B and C) suggest that RNA-seq undercounts RNA transfer. For example, the average percentage of transfer of ACTB, KRT8, PSAP and CCND1 mRNA as assayed using FISH is 5-10 fold higher than the estimate from RNA-seq (i.e. compare data in Figure 4C to that in Supplementary Data File 1 - Table 4). This difference could be either methodological or technical in origin, as smFISH measures the mRNA in unperturbed adherent cells, whereas for RNA-seq the cells are first detached from the surface by trypsin at $37^{\circ} \mathrm{C}$ and then sorted (at $4^{\circ} \mathrm{C}$ ) prior to RNA extraction. We have observed that the trypsinization and re-plating of acceptor MEFs leads to a massive loss in transferred ACTB-MBS mRNA, possibly through degradation (data not shown). On the other hand, RNA-seq library preparation may introduce bias in the detection of high abundance transcripts versus lower abundance ones at the reverse transcription and/or amplification levels. Thus, there is an experimental bias towards the detection of endogenous mRNAs, as compared to transferred mRNAs, and multiplex FISH methods may eventually prove more accurate. We note that the duration of our co-culture experiments was $12 \mathrm{hrs}$ and it is possible that longer durations might reveal a higher percentage of transfer. Although the transfer of $\beta$-actin-MBS mRNA reached a maximum within $2.5 \mathrm{hrs}$, and was maintained at the same level for at least $24 \mathrm{hrs}$ when either immortalized or primary MBS-MEFs were co-cultured with immortalized or primary wild-type MEFs (Haimovich et al., 2017), the transfer of $\beta$-actin-MBS mRNA continued to increase at least for up to 12 hrs when MBS-MEFs were co-cultured with MCF7 cells (Dasgupta and Gerst, 2020). Thus, greater levels of accumulation of transferred RNAs might occur depending upon cell type and growth conditions, as well as the RNA transfer rate and stability in the acceptor cells. 
Our results imply that nearly all human mRNA species, as well as some IncRNAs, can undergo transfer, yet what parameters limit the level of transfer, aside from relative gene expression, is unknown. As mRNAs and IncRNAs are localized to specific regions/organelles in cells (Buxbaum et al., 2015; Cabili et al., 2015), it may depend upon the ability of an RNA to localize, diffuse, or be targeted along with organelles to TNT entrance sites. Although mitochondria were shown to transfer through TNTs (Rustom et al., 2004; Sartori-Rupp et al., 2019; Wang et al., 2011; Zou et al., 2020), our RNA-seq results showed poor transfer of mitochondria-encoded RNAs relative to their expression (Supplementary Figure 2 and Supplementary File 1 - Table 4). It may be that TNT-mediated mitochondrial transfer is limited using our experimental conditions or that it may not be an efficient vehicle for transfer. On the other hand, limited live imaging data suggests that transfer is motorized (Haimovich et al., 2017) and, thus, the RNA might require specialized packaging or modification for transfer and recognition by TNT-specific motor proteins. This packaging or modification may distinguish RNAs targeted for transfer from non-transferred RNAs (Haimovich and Gerst, 2019). Thus, it is tempting to speculate that RNA molecules may be cotranscriptionally "marked" for transfer, especially since mRNA fate may be determined during transcription (Dahan and Choder, 2013; Haimovich et al., 2013; Nair et al., 2021; Slobodin and Dikstein, 2020; Trcek and Singer, 2010). Alternatively, transfer could be isoform-specific. However, the low read counts of transferred RNAs in our RNA-seq experiment may have prevented us from determining if they are enriched for specific transcription start sites, alternative poly-adenylation sites, or alternatively spliced isoforms. Understanding the mechanism of mRNA transfer will be key to further explore its physiological importance.

The findings of this study will enable us to answer if TNT-mediated RNA transfer plays a role in key biological processes, such as tumor growth, tissue differentiation and development as investigated for exosomes (Liu et al., 2018; Raulf et al., 2018). Our experimental system can be considered to be a simplistic recapitulation of a two dimensional human xenograft cancer model, where the human tumor cells (MCF7s) are in close proximity with mouse fibroblasts (MEFs). Based on our results, we speculate that fibroblasts in vivo could potentially acquire CAF-like phenotypes upon co-culture, as indicated by the transfer of prooncogenic RNAs to the MEFs (Figure 3D), as well as dramatic changes to the MEF transcriptome incurred upon co-culture (Figures 6 and 7, and 
Supplementary Figure 7). While at the moment we cannot exclude the possibility that the latter changes result from additional signaling pathways (e.g. paracrine, adhesion-dependent signaling, etc.), the idea that TNT-mediated RNA transfer could play a significant role should be considered. Although performed in vitro, our findings with immortalized cells may translate to in vivo systems, whereby tumorigenic or other signal-inducing RNAs transfer from cancer cells to surrounding stromal cells, CAFs, or immune cells. TNTs have been detected in multiple cancer types, such as bladder carcinoma, urothelial carcinoma, breast cancer, cervical carcinoma, colon cancer, glioblastoma, etc. (reviewed in (Roehlecke and Schmidt, 2020)). TNTs can then transport cargo to other cancer cells, which can increase intra-tumor heterogeneity or connect with cells in the tumor microenvironment to induce tumorigenic pathways. It is well known that RNAs derived from acute myelogenous leukemia (AML) cells make the bone marrow niche more permissive to tumor growth and evade chemotherapy (Hornick et al., 2016; Huan et al., 2015; Kumar et al., 2018). Furthermore, TNTs were shown to transport mutant forms of KRAS to induce ERK signaling in colorectal cancer cells and multidrug resistance P-glycoprotein in multiple cancer types (Ambudkar et al., 2005; Desir et al., 2019).

Aside from the tumor microenvironment, TNT-mediated RNA transfer probably has physiological functions under other conditions. We and others previously found that cellular stress conditions modulate TNT formation (Ariazi et al., 2017) and mRNA transfer (Haimovich et al., 2017). Thus, TNT mediated RNA transfer may have a role in maintaining tissue homeostasis or signaling under stress conditions. A particular example is the role of TNT in ocular homeostasis and pathology (Chinnery and Keller, 2020), and the recent discovery of TNT-mediated mRNA transfer in the retina (Ortin-Martinez et al., 2021). However, more work is needed to establish the role of TNT-mediated RNA transfer in vivo. Key to understanding the significance of this process is to determine the fate of transferred mRNAs, in terms of their translation, stability, and impact upon cell physiology.

Finally, it has not escaped our imagination that contact-dependent RNA transfer mechanisms could eventually be used as a novel strategy to deliver mRNA-based drugs in vivo (Kowalski et al., 2019; Sahin et al., 2014; Tang et al., 2019; Van Hoecke and Roose, 2019; Weng et al., 2020; Zhang et al., 2019a). Current strategies to administer in vitro transcribed mRNAs inside 
bioRxiv preprint doi: https://doi.org/10.1101/2021.11.28.470233; this version posted November 28, 2021. The copyright holder for this preprint (which was not certified by peer review) is the author/funder, who has granted bioRxiv a license to display the preprint in perpetuity. It is made available under aCC-BY-NC-ND 4.0 International license.

the body using transfection or encapsulation inside lipid nanoparticles are either ineffective or elicit potent immune responses and, thus, it may be feasible to employ exogenous cells as vehicles for gene therapy (Sahin et al., 2014). 


\section{Materials and Methods}

\section{Cell lines and culture conditions.}

Immortalized mouse embryonic fibroblast cells (MEFs) derived from WT and $\beta$-actin-MBS mice were described earlier (Lionnet et al., 2011). MCF7 cells were obtained from M.L. HEK293T cells were purchased from ATCC. All cell lines were cultured in DMEM (high glucose), supplemented with $10 \%$ Fetal Bovine Serum (FBS), $1 \mathrm{mM}$ sodium pyruvate and antibiotics $(0.1 \mathrm{mg} / \mathrm{mL}$ streptomycin and $10 \mathrm{U} / \mathrm{mL}$ penicillin) at $37^{\circ} \mathrm{C}$ with $5 \% \mathrm{CO}_{2}$. The cells were routinely cultured in 10 $\mathrm{cm}$ dishes and checked for mycoplasma infections by PCR using pan-Mycoplasma species-specific oligos (Dasgupta and Gerst, 2019).

\section{Plasmids and cell line generation}

tdTomato was subcloned from a previously described plasmid (Addgene plasmid \# 85453; gift of Aviv Regev, Broad Institute, MA) (Singer et al., 2016) into a pHAGE-UBC lentiviral vector behind a constitutive expression Ubiquitin C (UBC) promoter (obtained from R.H.S), leading to the creation of the pUBC-tdTomato plasmid. Fragments of $\beta$-actin were RT-PCR amplified (see Supplementary File 4 for primers) from cDNA derived from WT-MEFs and cloned after the stop codon of the tdTomato ORF of pUBC-tdTomato plasmid by restriction-free (RF) cloning (van den Ent and Lowe, 2006).

A lentiviral plasmid encoding the KRAB-dCas9-EGFP (pLV hU6-sgRNA hUbC-dCas9-KRABT2a-GFP) (Addgene plasmid \# 71237; gift from Charles Gersbach, Duke University, NC) (Thakore et al., 2015) was used as backbone to generate a Dox-inducible tdTomato system. Briefly, the UBC promoter was replaced by a TRE3GV promoter (taken from Addgene plasmid \# 85556; gift from Eric Lander, Broad Institute, MA) (Fulco et al., 2016), the KRAB-dCas9-EGFP was replaced by tdTomato, and the U6-sgRNA cassette was replaced by a rTet cassette under an UBC promoter (taken from Addgene plasmid \# 50917; gift from Rene Maehr and Scot Wolfe, University of Massachusetts Medical School, MA) (Kearns et al., 2014). All modifications were done by RF cloning. List of primers used are given in Supplementary File 4

Lentivirus particles were produced by transiently transfecting the expression plasmid with packaging plasmids VSVG, RRE and Rev (Addgene plasmids \# 12259, 12251, and 12253, 
respectively; gift from Didier Trono; EPFL, Switzerland) (Dull et al., 1998) into HEK293T cells using TransIT-Lenti transfection reagent (Mirus Bio) and allowed to grow for 72 hours. The viruscontaining media were harvested and concentrated with Lenti-X concentrator (Clontech) per the manufacturer's instructions. Virus particles were resuspended in complete DMEM, aliquoted, and stored in $-80^{\circ} \mathrm{C}$.

For all stable cell line generations (e.g. MBS-MEFs expressing either tdTomato- $\beta$-actin fragments or tdTomato expressed under the doxycycline-inducible promoter), 50,000 MBS-MEFs were seeded in 6-well plates and exposed to the virus particles mentioned above in serum-free media supplemented with $6 \mu \mathrm{g} / \mathrm{ml}$ polybrene (Sigma). Cells with high or low expression of tdTomato were selected by FACS (BD Biosciences Aria III).

\section{Cell sorting using magnetic microbeads}

We used an antigen-based cell sorting protocol slightly modified from the one we described earlier (Dasgupta and Gerst, 2020). Culture plates $(15 \mathrm{~cm}$ ) were coated with $10 \mu \mathrm{g} / \mathrm{mL}$ of Fibronectin (FN) (Sigma) in PBS for 20 minutes before plating the cells. For the Mix and Single culture samples, MBSMEF and MCF7 cells were cultured for about 15-18 hours on FN-coated plates before harvesting. For the Co-culture samples, MCF7 cells were plated first. Between 8-10 hours later, the MBS-MEF cells were plated, and co-culturing was maintained for additional 12 hours. At the time of harvesting, cells were trypsinized using $3 \mathrm{ml}$ of $0.25 \%$ Trypsin (Sigma) and resuspended in $500 \mu \mathrm{l}$ of cold DMEM (supplemented with FBS). In order to have good cell separation, we noted that the optimum amount of antibodies and incubation times differ for MEF and MCF7 cells. For each biological replicate we used duplicate "Mix" and "Co-culture" samples - one used to enrich for MCF7 cells and the other to enrich for MEFs. Cells were incubated on ice with magnetic beadconjugated anti-CD326 microbeads (Miltenyi Biotec $\mathrm{GmBH}$ ), as described in the table below: 


\begin{tabular}{|c|c|c|c|c|}
\hline $\begin{array}{l}\text { Cell type to be } \\
\text { enriched }\end{array}$ & Sample type & $\begin{array}{l}\text { Number } \\
\text { of cells }\end{array}$ & $\begin{array}{l}\text { Amount of anti- } \\
\text { CD326 microbeads } \\
\text { added }\end{array}$ & $\begin{array}{l}\text { Time of } \\
\text { incubation }\end{array}$ \\
\hline \multirow[t]{3}{*}{ MBS-MEF } & Single Culture & $3 \times 10^{6}$ & \multirow{3}{*}{$\begin{array}{l}100 \mu l \text { in a total of } 500 \\
\mu l \text { cell suspension }\end{array}$} & \multirow[t]{3}{*}{$30 \mathrm{~min}$ on ice } \\
\hline & Mix & $3 \times 10^{6}$ & & \\
\hline & Co-culture & $2 \times 10^{6}$ & & \\
\hline \multirow[t]{3}{*}{ MCF7 } & Single Culture & $3 \times 10^{6}$ & \multirow{3}{*}{$\begin{array}{l}10 \mu \mathrm{l} \text { in a total of } 500 \\
\mu l \text { cell suspension }\end{array}$} & \multirow[t]{3}{*}{10 min on ice } \\
\hline & Mix & $3 \times 10^{6}$ & & \\
\hline & Co-culture & $2 \times 10^{6}$ & & \\
\hline
\end{tabular}

Thereafter, an additional $1 \mathrm{ml}$ of cold, complete DMEM (with FBS) was added to the cell suspension and sorted using MACS LS columns (Miltenyi Biotec $\mathrm{GmBH}$ ). The columns were washed two times with $1 \mathrm{ml}$ of cold DMEM each. The flow-through contains the CD326-negative MBS-MEF fraction, while the CD326-positive MCF7 fraction remains attached to the magnetic bead column. The MCF7 fraction was eluted with $3 \mathrm{ml}$ of cold DMEM using the supplied plunger. To increase the purity of the MCF7 or MEF fraction, the flow-through (MEFs) or eluate (MCF7s) was sorted again using a fresh MACS LS column, as described above. A small aliquot $\left(\sim 1 / 10^{\text {th }}\right)$ of the sorted MBS-MEF and MCF7 cell populations was then counterstained with Alexa-488-labeled anti-human CD326 (Biolegend; Cat \#: 324210) and PE-labeled anti-mouse CD321 antibody (BD Biosciences, Cat \#: 564908). For both antibodies, $5 \mu$ l of antibody per million cells were used and the sorting efficiency was checked using a flow cytometer (Attune NXT, Thermo Scientific). Samples belonging to replicate experiments were collected at the same time to reduce the batch effect. To evaluate the contamination in MEF-enriched samples, only the CD326-high and CD321-low quadrant was considered as contaminating MCF7 cells in MEF enriched fractions. To evaluate the level of MEF contamination in the MCF7-enriched sample, the CD326-low and CD321-high quadrant was considered as contaminant. These numbers are summarized in Table 1. Note that there is a low percentage of double CD321-CD326 positive-stained cells (upper right quadrant) which is probably due to non-specific staining with the antibodies, as it appears in single cultures as well (Supplementary Figure 1, Table 1 “\% False positive”). There is also a small percentage of unstained cells (lower left quadrant). These are probably MEFs, since these are relatively abundant in MEFenriched populations (0.1-2.8\%), but rare events in the MCF7-enriched populations (0-0.08\%). 


\section{RNA extraction, quality control, library preparation and sequencing}

Total RNA was extracted using the NucleoSpin RNA Mini kit (Macharey Nagel) and RNA integrity checked using an Agilent Tapestation 2100, while the RNA concentration was measured using a NanoDrop microvolume spectrophotometer and Qubit 2.0 BR assay. Transfer of human $\beta$-actin from MCF7 to MBS-MEF was verified by RT-PCR and RT-qPCR using oligos specific for human $\beta$ actin (Supplementary File 4). Poly-A(+) RNA sequencing libraries were prepared using the NEBNext Ultra II Directional RNA Library Prep Kit (New England Biolabs). Two $\mu g$ of RNA per sample were processed in two separate reactions (separate technical replicas) to increase depth. Libraries were amplified by 8 PCR cycles and sequenced on a Novaseq 6000 SP1 flowcell using 2x150 bp pairedend reads. The processed files have been deposited in the Gene Expression Omnibus (GEO) $\begin{array}{llll}\text { Database } & \text { the } & \text { GScession } & \text { number }\end{array}$ (https://www.ncbi.nlm.nih.gov/geo/query/acc.cgi?acc=GSE185002).

\section{Post processing and alignment to reference genomes}

Identification of human-specific reads was done in multiple sequential steps (Supplementary Figure 1B). First, fastq reads were trimmed from their adapter using cutadapt and aligned to the human genome (hg38) using STAR (v 2.7.3a) (Dobin and Gingeras, 2016; Martin, 2011). The alignment was done without soft clipping (--alignEndsType EndToEnd) and using -outFilterMismatchNoverLmax 0.0. Second, the alignment was filtered to contain only paired-end reads with unique alignment. Third, uniquely-aligned reads were re-aligned to the mouse genome (mm10) using the same criteria. Finally, for every read the number of differences to the human genome was compared to the number of differences to the mouse genome. Only the reads that aligned to the human genome with zero mismatches and aligned to mouse with $>2$ differences were considered as bonafide human reads and were considered for further analysis. The same approach was applied to identify mouse-specific genes in human-enriched samples. HTseq was used to count the number of reads per gene. The read count was normalized to the library size of each sample (reads per million, RPM). All fastq data and raw read count data have been deposited in the Gene Expression Omnibus (GEO) Database under the accession number GSE185002. 


\section{Statistical analysis to detect transferred genes and differential gene expression}

Exploratory analysis (hierarchical clustering and principal component analysis) of the count data was done using the base functions in R. To detect the most abundantly transferred human mRNAs we compared the normalized read count of the Co-culture samples to that of the Mix samples using an unpaired, one-tailed t-test, followed by multiple testing correction (Benjamini, Krieger, \& Yekutieli procedure). Genes with a FC $\geq 2$ and False Discovery Rate (FDR) $<5 \%$ were considered as enriched in the co-culture samples. Other statistical packages, such as DESeq2 or edgeR, which average the dispersion of the same gene across different samples are not useful here as we compared samples of different RNA content. Indeed, DESeq2 did not detect any significantly transferred genes between the Mix and Co-culture samples. We also performed a non-parametric rank analysis to check if the relative ranks of certain genes are different between Co-culture and Mix. Using this test, we failed to detect the transfer of $\beta$-actin as a significant observation (not shown), in contrast to our previous FISH results (Dasgupta and Gerst, 2020).

To estimate the proportion of the donor mRNAs that undergoes transfer, we defined the per gene "percentage transfer" as: Percentage transfer = [[Avg. RPM (Co-culture) - Avg. RPM (Mix) $x$ 100] / [Avg. RPM (MCF7 Single Culture)]]. To minimize the noise from the low-expressed genes, genes with $\mathrm{RPM}<100$ for the Single culture and $<10$ for the Co-culture and FC $<2$ were not considered.

To estimate the gene expression level of the native mouse transcriptome, and to test the differential expression between the different conditions, the HTseq counts were processed using DEseq2 for normalization and differential expression testing (Love et al., 2014). A gene was considered as having a differential expression if the absolute value of the log 2 fold change between

conditions was at least 1 , the $p_{\text {adj }}$ (false discovery rate; FDR) $<0.05$ (Benjamini-Hochberg correction), and the gene has at least 50 normalized counts in at least two samples.

\section{Motif enrichment analysis of transferred genes}

The top 283 transferred genes (as obtained in the previous section) were converted to their ENSEMBL transcript ID of the longest splice variant and the 5' UTR, CDS and 3' UTR of each gene 
extracted using the "table browser" tool of the UCSC genome browser by annotating to the GENCODE V38 database (exported in FASTA format). The 5' UTR, CDS and the 3' UTR of the genes were then analyzed separately using the "Motif Discovery" mode of MEME Suite using the following inputs: Mode: Classic; Input Type: DNA/RNA; Zero or one occurrence per sequence (zoops); maximum width: 15; return top 3 motifs. No motifs were identified among the two UTRs, while the top three motifs in the coding sequence are shown. As a comparison, similar analysis were done on groups of 280-300 genes among the pool of less transferred genes and the top three motifs of each group were identified.

\section{Doxycycline induction experiments}

In a 12 -well plate, inducible tdTomato cells $\left(2.5 \times 10^{4}\right.$ for co-culture and $5 \times 10^{4}$ for monoculture) were plated onto fibronectin-coated glass cover slips in the presence of $4 \mu \mathrm{g} / \mathrm{ml}, 2 \mu \mathrm{g} / \mathrm{ml}$, or 0 $\mu \mathrm{g} / \mathrm{ml}$ Doxycycline. After $24 \mathrm{~h}$, the medium and Doxycycline were replaced, and WT MEFs (4x10 for co-culture and $8 \times 10^{4}$ for monoculture) were plated on top of the tdTomato cells. In parallel, a WT MEF monoculture sample (negative control) was cultured in the presence of $4 \mu \mathrm{g} / \mathrm{ml}$ of Doxycycline. After 16 hours, all samples were subjected to smFISH.

\section{Single molecule fluorescent in situ hybridization (smFISH)}

smFISH was carried out according to a previously described protocol (Haimovich et al., 2017; Haimovich and Gerst, 2018; Haimovich and Gerst, 2019). A set of Cy5-labeled FISH probes to detect tdTomato mRNA and Quasar (Q) 570-labeled FISH probes for KRT8 mRNA (Zuckerman et al., 2020) were generous gifts from Shalev Itzkovitch and Igor Ulitsky (Weizmann Institute of Science), respectively. Q570-labeled FISH probes for CCND1 and PSAP were obtained from LGC Biosearch Technologies. Cy5-labelled probes for MBS were reported previously (Dasgupta and Gerst, 2020; Haimovich et al., 2017).

\section{Widefield imaging}

Images of tdTomato smFISH experiments were captured using a Zeiss AxioObserver Z1 DuoLink dual camera imaging system equipped with an Illuminator HXP 120-V light source, Plan 
Apochromat $100 \times 1.4$ NA oil-immersion objective, and a Hamamatsu Flash 4 sCMOS camera. Thirty $0.2 \mu \mathrm{m}$ step $z$-stack images were taken using a motorized XYZ scanning stage $130 \times 100$ Piezo, and ZEN2 software at $0.0645 \mu \mathrm{m}$ per pixel or $0.130 \mu \mathrm{m}$ per pixel. All other images were captured with a Nikon Ti2 series inverted microscope equipped with a Du-888 CCD camera and 100x oilimmersion objective. Thirty $0.2 \mu \mathrm{m}$ step z-stack images were taken using NIS Elements software at $0.130 \mu \mathrm{m}$ per pixel.

\section{Image analysis and presentation}

The number of mRNAs (FISH spots) were scored using a MATLAB based GUI program, FISH-Quant (FQ), as described (Mueller et al., 2013; Tsanov et al., 2016). Briefly, outlines of both the cell and nucleus for all cells were demarcated by the "Define Outlines" functions. In co-culture samples, acceptor cells were distinguished from donor cells by visual identification, presence of transcription sites, and the high expression of query RNAs. Donor cells had significantly more smFISH-labeled RNA spots and had bright transcription sites in the nucleus. Thereafter, FISH spots were characterized from the donor cells (as the positive control) and detection settings were then applied to all cells in the same batch of analysis. Typically, one donor cell is filtered for background removal (typical parameters for filtering in FQ were Kernel BGD XY, Z =6, 5; Kernel SNR XY, Z =0.5, 1) and the individual spots were approximately determined by fitting them to a 3D Gaussian function. Due to high background in the nucleus, spots were only detected in the cytoplasm. Apparent non-specific spots were discarded by adjusting for the intensity and the width of Gaussian function. The detection settings thus obtained were applied to all cells (e.g. other donor cells, acceptor cells only, and the acceptor cells in co-culture) using the "batch processing" tool. Once FQ preliminarily counted the number of spots in all the cells, the image parameters (e.g. Sigma XY, Sigma Z, Signal Amplitude and Background) were adjusted so as to have as minimum number of spots as possible in cells that do not express the relevant mRNA (i.e. acceptor cells alone). The modified detection settings were then re-applied to all cells to determine the number of spots in each cell. For image presentation, representative cells from each condition was minimally adjusted for brightness and contrast in Fiji (Schindelin et al., 2012) and a RGB picture was generated by assigning an appropriate Look Up Table (LUT) to each channel. 


\section{Quadrapod and conditioned media experiments}

To check for mRNA transfer from MCF7 cells to MBS-MEFs via EVs, MBS-MEFs and MCF7 cells were either spatially separated (i.e. the quadrapod experiment) or MBS-MEFs were cultured in conditioned media derived from MCF7 cells. For the quadrapod experiment, $15 \mathrm{~cm}$ cell culture plates were cut to $12 \mathrm{~cm}$ wide circular shapes from $15 \mathrm{~cm}$ tissue culture plates at the Scientific Instrumentation workshop of the Weizmann Institute. Four Perspex legs ( $2 \mathrm{~mm}$ in height) per disk were set in a square arrangement, as indicated in Supplementary Figure 7. Disks were perforated with $1 \mathrm{~mm}$-wide holes to allow proper aeration and avoid formation of bubbles. All disks were washed in $70 \%$ EtOH for minimum of $24 \mathrm{hrs}$ before use. Disks were stored under sterile conditions at room temperature until used. First, $3 \times 10^{6} \mathrm{MCF} 7$ cells were cultured on fibronectin-coated disks for $6 \mathrm{hrs}$. Second, $3 \times 10^{6}$ MBS-MEF cells were seeded onto a separate $12 \mathrm{~cm}$ fibronectin-coated disk and cultured in a $15 \mathrm{~cm}$ plate. After 10 minutes of MBS-MEF cells attaching to the fibronectincoated disk, the disk containing MCF7 cells was then placed over the disk containing MBS-MEF cells, so that the two cell types face each other, and were cultured for an additional $12 \mathrm{hrs}$. For the conditioned media experiment, culture media was harvested from $3 \times 10^{6} \mathrm{MCF} 7$ cells, centrifuged for $10 \mathrm{~min}$ at $500 \mathrm{xg}$ and added to $3 \times 10^{6} \mathrm{MBS}-\mathrm{MEF}$ in a separate culture plate. Empty quadrapods were used in Single MEF, Co-culture and conditioned media samples to equalize any effect of aeration. Cells were then trypsinized and sorted using magnetic beads as described above, prior to the detection of human mRNAs in the purified MEF-enriched fraction by qRT-PCR.

\section{Statistical analysis}

The results from Figures 4 and 5, and Supplementary Figure 4 were compared by using the one way ANOVA followed by a pair-wise Tukey's test to estimate the corrected P value for each pair of indicated corrections. P values from Supplementary Figure 4 are tabulated in Table 2. All indicated calculations were performed using GraphPad Prism software Version 7 (GraphPad Software, Inc.).

\section{Acknowledgements:}


We thank Ester Feldmesser (Weizmann Institute of Science, Israel) for assistance with the bioinformatics analysis and Michael Wigler and Siran Li (Cold Spring Harbor Laboratories, NY, USA) for generously performing scBAG-seq experiments to detect mRNA transfer. This work was funded by grants to J.E.G. from the Joel and Mady Dukler Fund for Cancer Research, the Jean-Jacques Brunschwig Fund for the Molecular Genetics of Cancer, a Proof-of-Principle Grant from the Moross Integrated Cancer Center, the Kekst Family Institute for Medical Genetics (Weizmann Institute of Science), the German-Israel Foundation (GIF; I-1461-412.13/2018) (J.E.G and M.L), and the USIsrael Binational Science Foundation-National Science Foundation (\#2015846) (J.E.G and R.H.S).

\section{Author contributions}

S.D. and D.Y.D. performed the experiments; S.D. developed the cell separation protocol; G.H. conceived the project; S.D., D.Y.D. and J.E.G. did the figure preparation; and G.H. and J.E.G. designed the experiments and supervised the project. E.W. prepared the RNA-seq libraries and performed the sequencing. T.O. and S.D. performed bioinformatics and statistical analysis. S.D., G.H. and J.E.G. wrote and edited the manuscript. R.H.S., M.L., and J.E.G. secured funding.

\section{Declaration of interests}

The authors declare no competing interests. 


\section{References}

Abounit, S., Wu, J.W., Duff, K., Victoria, G.S., and Zurzolo, C. (2016). Tunneling nanotubes: A possible highway in the spreading of tau and other prion-like proteins in neurodegenerative diseases. Prion 10: 344351.

Ambudkar, S.V., Sauna, Z.E., Gottesman, M.M., and Szakacs, G. (2005). A novel way to spread drug resistance in tumor cells: functional intercellular transfer of P-glycoprotein (ABCB1). Trends Pharmacol Sci 26: 385-387.

Ariazi, J., Benowitz, A., De Biasi, V., Den Boer, M.L., Cherqui, S., Cui, H., Douillet, N., Eugenin, E.A., Favre, D., Goodman, S., et al. (2017). Tunneling Nanotubes and Gap Junctions-Their Role in Long-Range Intercellular Communication during Development, Health, and Disease Conditions. Front Mol Neurosci 10: 333.

Ashley, J., Cordy, B., Lucia, D., Fradkin, L.G., Budnik, V., and Thomson, T. (2018). Retrovirus-like Gag Protein Arc1 Binds RNA and Traffics across Synaptic Boutons. Cell 172: 262-274.e211.

Axelsen, J.B., Lotem, J., Sachs, L., and Domany, E. (2007). Genes overexpressed in different human solid cancers exhibit different tissue-specific expression profiles. Proc Natl Acad Sci USA 104: 13122-13127.

Bailey, T.L., Boden, M., Buske, F.A., Frith, M., Grant, C.E., Clementi, L., Ren, J., Li, W.W., and Noble, W.S. (2009). MEME SUITE: tools for motif discovery and searching. Nucleic Acids Res 37: W202-208.

Batagov, A.O., and Kurochkin, I.V. (2013). Exosomes secreted by human cells transport largely mRNA fragments that are enriched in the 3'-untranslated regions. Biol Direct 8: 12.

Berardocco, M., Radeghieri, A., Busatto, S., Gallorini, M., Raggi, C., Gissi, C., D'Agnano, I., Bergese, P., Felsani, A., and Berardi, A.C. (2017). RNA-seq reveals distinctive RNA profiles of small extracellular vesicles from different human liver cancer cell lines. Oncotarget 8: 82920-82939.

Biran, A., Perelmutter, M., Gal, H., Burton, D.G., Ovadya, Y., Vadai, E., Geiger, T., and Krizhanovsky, V. (2015). Senescent cells communicate via intercellular protein transfer. Genes Dev 29: 791-802.

Blumberg, A., Zhao, Y., Huang, Y.F., Dukler, N., Rice, E.J., Chivu, A.G., Krumholz, K., Danko, C.G., and Siepel, A. (2021). Characterizing RNA stability genome-wide through combined analysis of PRO-seq and RNA-seq data. BMC Biol 19: 30.

Brennecke, P., Anders, S., Kim, J.K., Kolodziejczyk, A.A., Zhang, X., Proserpio, V., Baying, B., Benes, V., Teichmann, S.A., Marioni, J.C., et al. (2013). Accounting for technical noise in single-cell RNA-seq experiments. Nat Methods 10: 1093-1095. 
Buxbaum, A.R., Haimovich, G., and Singer, R.H. (2015). In the right place at the right time: visualizing and understanding mRNA localization. Nat Rev Mol Cell Biol 16: 95-109.

Cabili, M.N., Dunagin, M.C., McClanahan, P.D., Biaesch, A., Padovan-Merhar, O., Regev, A., Rinn, J.L., and Raj, A. (2015). Localization and abundance analysis of human IncRNAs at single-cell and single-molecule resolution. Genome Biol 16: 20.

Calderwood, A., Kopriva, S., and Morris, R.J. (2016). Transcript Abundance Explains mRNA Mobility Data in Arabidopsis thaliana. Plant Cell 28: 610-615.

Chinnery, H.R., and Keller, K.E. (2020). Tunneling Nanotubes and the Eye: Intercellular Communication and Implications for Ocular Health and Disease. Biomed Res Int 2020: 7246785.

Cordero Cervantes, D., and Zurzolo, C. (2021). Peering into tunneling nanotubes-The path forward. EMBO J 40: e105789.

Dahan, N., and Choder, M. (2013). The eukaryotic transcriptional machinery regulates mRNA translation and decay in the cytoplasm. Biochim Biophys Acta 1829: 169-173.

Dasgupta, S., and Gerst, J.E. (2019). Testing for mycoplasma in cell culture by PCR. In Bio-Protocol (Bio-101).

Dasgupta, S., and Gerst, J.E. (2020). A Protocol for Non-biased Identification of RNAs Transferred Between Heterologous Mammalian Cell Types Using RNA Tagging, Cell Sorting, and Sequencing. Methods Mol Biol 2166: 195-214.

Desir, S., Wong, P., Turbyville, T., Chen, Shetty, M., Clark, C., Zhai, E., Romin, Y., Manova-Todorova, K., Starr, T.K., et al. (2019). Intercellular Transfer of Oncogenic KRAS via Tunneling Nanotubes Introduces Intracellular Mutational Heterogeneity in Colon Cancer Cells. Cancers (Basel) 11: 892.

Dobin, A., and Gingeras, T.R. (2016). Optimizing RNA-Seq Mapping with STAR. Methods Mol Biol 1415: 245262.

Dreux, M., Garaigorta, U., Boyd, B., Decembre, E., Chung, J., Whitten-Bauer, C., Wieland, S., and Chisari, F.V. (2012). Short-range exosomal transfer of viral RNA from infected cells to plasmacytoid dendritic cells triggers innate immunity. Cell Host Microbe 12: 558-570.

Dull, T., Zufferey, R., Kelly, M., Mandel, R.J., Nguyen, M., Trono, D., and Naldini, L. (1998). A third-generation lentivirus vector with a conditional packaging system. J Virol 72: 8463-8471. 
Ekstrom, K., Valadi, H., Sjostrand, M., Malmhall, C., Bossios, A., Eldh, M., and Lotvall, J. (2012). Characterization of mRNA and microRNA in human mast cell-derived exosomes and their transfer to other mast cells and blood CD34 progenitor cells. J Extracell Vesicles 1: 18389.

Elyada, E., Bolisetty, M., Laise, P., Flynn, W.F., Courtois, E.T., Burkhart, R.A., Teinor, J.A., Belleau, P., Biffi, G., Lucito, M.S., et al. (2019). Cross-species single-cell analysis of pancreatic ductal adenocarcinoma reveals antigen-presenting cancer-associated fibroblasts. Cancer Discovery 9: 1102-1123.

Eng, C.L., Lawson, M., Zhu, Q., Dries, R., Koulena, N., Takei, Y., Yun, J., Cronin, C., Karp, C., Yuan, G.C., et al. (2019). Transcriptome-scale super-resolved imaging in tissues by RNA seqFISH. Nature 568: 235-239.

Eugenin, E.A., Gaskill, P.J., and Berman, J.W. (2009). Tunneling nanotubes (TNT) are induced by HIVinfection of macrophages: a potential mechanism for intercellular HIV trafficking. Cell Immunol 254: 142148.

Fabregat, A., Korninger, F., Viteri, G., Sidiropoulos, K., Marin-Garcia, P., Ping, P., Wu, G., Stein, L., D'Eustachio, P., and Hermjakob, H. (2018). Reactome graph database: Efficient access to complex pathway data. PLoS Comput Biol 14: e1005968.

Fabregat, A., Sidiropoulos, K., Viteri, G., Forner, O., Marin-Garcia, P., Arnau, V., D'Eustachio, P., Stein, L., and Hermjakob, H. (2017). Reactome pathway analysis: a high-performance in-memory approach. BMC Bioinformatics 18: 142.

Florio, M., Heide, M., Pinson, A., Brandl, H., Albert, M., Winkler, S., Wimberger, P., Huttner, W.B., and Hiller, M. (2018). Evolution and cell-type specificity of human-specific genes preferentially expressed in progenitors of fetal neocortex. Elife 7: e32332.

Fulco, C.P., Munschauer, M., Anyoha, R., Munson, G., Grossman, S.R., Perez, E.M., Kane, M., Cleary, B., Lander, E.S., and Engreitz, J.M. (2016). Systematic mapping of functional enhancer-promoter connections with CRISPR interference. Science 354: 769-773.

Goodman, S., Naphade, S., Khan, M., Sharma, J., and Cherqui, S. (2019). Macrophage polarization impacts tunneling nanotube formation and intercellular organelle trafficking. Sci Rep 9: 14529.

Guo, R., Katz, B.B., Tomich, J.M., Gallagher, T., and Fang, Y. (2016). Porcine Reproductive and Respiratory Syndrome Virus Utilizes Nanotubes for Intercellular Spread. J Virol 90: 5163-5175.

Haimovich, G., Choder, M., Singer, R.H., and Trcek, T. (2013). The fate of the messenger is pre-determined: a new model for regulation of gene expression. Biochim Biophys Acta 1829: 643-653. 
Haimovich, G., Dasgupta, S., and Gerst, J.E. (2021). RNA transfer through tunneling nanotubes. Biochem Soc Trans 49: 145-160.

Haimovich, G., Ecker, C.M., Dunagin, M.C., Eggan, E., Raj, A., Gerst, J.E., and Singer, R.H. (2017). Intercellular mRNA trafficking via membrane nanotube-like extensions in mammalian cells. Proc Natl Acad Sci USA 114: E9873-E9882.

Haimovich, G., and Gerst, J.E. (2018). Single-molecule Fluorescence in situ Hybridization (smFISH) for RNA Detection in Adherent Animal Cells. Bio Protoc 8: e3070.

Haimovich, G., and Gerst, J.E. (2019). Detection of mRNA Transfer Between Mammalian Cells in Coculture by Single-Molecule Fluorescent In Situ Hybridization (smFISH). Methods Mol Biol 2038: 109-129.

Hofmann, N.R. (2016). Should i stay or should i go? Abundance as a new null hypothesis for determination of mRNA mobility. Plant Cell 28: 597-598.

Hornick, N.I., Doron, B., Abdelhamed, S., Huan, J., Harrington, C.A., Shen, R., Cambronne, X.A., Chakkaramakkil Verghese, S., and Kurre, P. (2016). AML suppresses hematopoiesis by releasing exosomes that contain microRNAs targeting c-MYB. Sci Signal 9: ra88.

Huan, J., Hornick, N.I., Goloviznina, N.A., Kamimae-Lanning, A.N., David, L.L., Wilmarth, P.A., Mori, T., Chevillet, J.R., Narla, A., Roberts, C.T., Jr., et al. (2015). Coordinate regulation of residual bone marrow function by paracrine trafficking of AML exosomes. Leukemia 29: 2285-2295.

Huang da, W., Sherman, B.T., and Lempicki, R.A. (2009a). Bioinformatics enrichment tools: paths toward the comprehensive functional analysis of large gene lists. Nucleic Acids Res 37: 1-13.

Huang da, W., Sherman, B.T., and Lempicki, R.A. (2009b). Systematic and integrative analysis of large gene lists using DAVID bioinformatics resources. Nat Protoc 4: 44-57.

Huang, N.C., and Yu, T.S. (2009). The sequences of Arabidopsis GA-INSENSITIVE RNA constitute the motifs that are necessary and sufficient for RNA long-distance trafficking. Plant J 59: 921-929.

Jafari, R., Rahbarghazi, R., Ahmadi, M., Hassanpour, M., and Rezaie, J. (2020). Hypoxic exosomes orchestrate tumorigenesis: molecular mechanisms and therapeutic implications. J Transl Med 18: 474.

Jiang, H., Li, Z., Li, X., and Xia, J. (2015). Intercellular transfer of messenger RNAs in multiorgan tumorigenesis by tumor cell-derived exosomes. Mol Med Rep 11: 4657-4663.

Kanehisa, M., and Goto, S. (2000). KEGG: kyoto encyclopedia of genes and genomes. Nucleic Acids Res 28: 27-30. 
Kearns, N.A., Genga, R.M., Enuameh, M.S., Garber, M., Wolfe, S.A., and Maehr, R. (2014). Cas9 effectormediated regulation of transcription and differentiation in human pluripotent stem cells. Development 141: 219-223.

Kim, B.W., Lee, J.S., and Ko, Y.G. (2019). Mycoplasma exploits mammalian tunneling nanotubes for cell-tocell dissemination. BMB Rep 52: 490-495.

Kolba, M.D., Dudka, W., Zareba-Koziol, M., Kominek, A., Ronchi, P., Turos, L., Chroscicki, P., Wlodarczyk, J., Schwab, Y., Klejman, A., et al. (2019). Tunneling nanotube-mediated intercellular vesicle and protein transfer in the stroma-provided imatinib resistance in chronic myeloid leukemia cells. Cell Death Dis 10: 817.

Kolodny, G.M. (1971). Evidence for transfer of macromolecular RNA between mammalian cells in culture. Exp Cell Res 65: 313-324.

Kolodny, G.M. (1972). Cell to cell transfer of RNA into transformed cells. J Cell Physiol 79: 147-150.

Korenkova, O., Pepe, A., and Zurzolo, C. (2020). Fine intercellular connections in development: TNTs, cytonemes, or intercellular bridges? Cell Stress 4: 30-43.

Kowalski, P.S., Rudra, A., Miao, L., and Anderson, D.G. (2019). Delivering the Messenger: Advances in Technologies for Therapeutic mRNA Delivery. Mol Ther 27: 710-728.

Kumar, B., Garcia, M., Weng, L., Jung, X., Murakami, J.L., Hu, X., McDonald, T., Lin, A., Kumar, A.R., DiGiusto, D.L., et al. (2018). Acute myeloid leukemia transforms the bone marrow niche into a leukemia-permissive microenvironment through exosome secretion. Leukemia 32: 575-587.

Lau, C.S., and Wong, D.T. (2012). Breast cancer exosome-like microvesicles and salivary gland cells interplay alters salivary gland cell-derived exosome-like microvesicles in vitro. PLoS One 7: e33037.

Li, M., Zeringer, E., Barta, T., Schageman, J., Cheng, A., and Vlassov, A.V. (2014). Analysis of the RNA content of the exosomes derived from blood serum and urine and its potential as biomarkers. Philos Trans $R$ Soc Lond B Biol Sci 369.

Li, S., Kendall, J., Park, S., Wang, Z., Alexander, J., Moffitt, A., Ranade, N., Danyko, C., Gegenhuber, B., Fischer, S., et al. (2020). Copolymerization of single-cell nucleic acids into balls of acrylamide gel. Genome Res 30: 49-61. 
Lionnet, T., Czaplinski, K., Darzacq, X., Shav-Tal, Y., Wells, A.L., Chao, J.A., Park, H.Y., de Turris, V., LopezJones, M., and Singer, R.H. (2011). A transgenic mouse for in vivo detection of endogenous labeled mRNA. Nat Methods 8: 165-170.

Liu, Y., Wang, H., and Wang, J. (2018). Exosomes as a novel pathway for regulating development and diseases of the skin. Biomed Rep 8: 207-214.

Ljubojevic, N., Henderson, J.M., and Zurzolo, C. (2021). The Ways of Actin: Why Tunneling Nanotubes Are Unique Cell Protrusions. Trends Cell Biol 31: 130-142.

Love, M.I., Huber, W., and Anders, S. (2014). Moderated estimation of fold change and dispersion for RNAseq data with DESeq2. Genome Biol 15: 550.

Lu, J.J., Yang, W.M., Li, F., Zhu, W., and Chen, Z. (2019). Tunneling Nanotubes Mediated microRNA-155 Intercellular Transportation Promotes Bladder Cancer Cells' Invasive and Proliferative Capacity. Int J Nanomedicine 14: 9731-9743.

Martin, M. (2011). Cutadapt removes adapter sequences from high-throughput sequencing reads. EMBnetjournal 17: 10-10.

Matsuno, Y., Kanke, T., Maruyama, N., Fujii, W., Naito, K., and Sugiura, K. (2019). Characterization of mRNA profiles of the exosome-like vesicles in porcine follicular fluid. PLoS One 14: e0217760.

Mittelbrunn, M., Gutierrez-Vazquez, C., Villarroya-Beltri, C., Gonzalez, S., Sanchez-Cabo, F., Gonzalez, M.A., Bernad, A., and Sanchez-Madrid, F. (2011). Unidirectional transfer of microRNA-loaded exosomes from T cells to antigen-presenting cells. Nat Commun 2: 282.

Mortazavi, A., Williams, B.A., McCue, K., Schaeffer, L., and Wold, B. (2008). Mapping and quantifying mammalian transcriptomes by RNA-Seq. Nat Methods 5: 621-628.

Mueller, F., Senecal, A., Tantale, K., Marie-Nelly, H., Ly, N., Collin, O., Basyuk, E., Bertrand, E., Darzacq, X., and Zimmer, C. (2013). FISH-quant: Automatic counting of transcripts in 3D FISH images. Nat Methods 10: 277-278.

Murray, L.M.A., and Krasnodembskaya, A.D. (2019). Intercellular Communication Via Organelle Transfer in the Biology and Therapeutic Applications of Stem Cells. Stem Cells 37: 14-25.

Nair, R.R., Zabezhinsky, D., Gelin-Licht, R., Haas, B.J., Dyhr, M.C., Sperber, H.S., Nusbaum, C., and Gerst, J.E. (2021). Multiplexed mRNA assembly into ribonucleoprotein particles plays an operon-like role in the control of yeast cell physiology. Elife 10: e66050. 
Ni, W.D., Yang, Z.T., Cui, C.A., Cui, Y., Fang, L.Y., and Xuan, Y.H. (2017). Tenascin-C is a potential cancerassociated fibroblasts marker and predicts poor prognosis in prostate cancer. Biochem Biophys Res Commun 486: 607-612.

Nik-Zainal, S., Davies, H., Staaf, J., Ramakrishna, M., Glodzik, D., Zou, X., Martincorena, I., Alexandrov, L.B., Martin, S., Wedge, D.C., et al. (2016). Landscape of somatic mutations in 560 breast cancer whole-genome sequences. Nature 534: 47-54.

Notaguchi, M., Higashiyama, T., and Suzuki, T. (2015). Identification of mRNAs that move over long distances using an RNA-Seq analysis of Arabidopsis/Nicotiana benthamiana heterografts. Plant Cell Physiol 56: 311-321.

O'Brien, K., Breyne, K., Ughetto, S., Laurent, L.C., and Breakefield, X.O. (2020). RNA delivery by extracellular vesicles in mammalian cells and its applications. Nat Rev Mol Cell Biol 21: 585-606.

Onfelt, B., Nedvetzki, S., Benninger, R.K., Purbhoo, M.A., Sowinski, S., Hume, A.N., Seabra, M.C., Neil, M.A., French, P.M., and Davis, D.M. (2006). Structurally distinct membrane nanotubes between human macrophages support long-distance vesicular traffic or surfing of bacteria. J Immunol 177: 8476-8483.

Ortin-Martinez, A., Yan, N.E., Tsai, E.L.S., Comanita, L., Gurdita, A., Tachibana, N., Liu, Z.C., Lu, S., Dolati, P., Pokrajac, N.T., et al. (2021). Photoreceptor nanotubes mediate the in vivo exchange of intracellular material. EMBO J e107264.

Panasiuk, M., Rychlowski, M., Derewonko, N., and Bienkowska-Szewczyk, K. (2018). Tunneling Nanotubes as a Novel Route of Cell-to-Cell Spread of Herpesviruses. J Virol 92: e00090.

Pastuzyn, E.D., Day, C.E., Kearns, R.B., Kyrke-Smith, M., Taibi, A.V., McCormick, J., Yoder, N., Belnap, D.M., Erlendsson, S., Morado, D.R., et al. (2018). The Neuronal Gene Arc Encodes a Repurposed Retrotransposon Gag Protein that Mediates Intercellular RNA Transfer. Cell 172: 275-288.e218.

Pein, M., Insua-Rodriguez, J., Hongu, T., Riedel, A., Meier, J., Wiedmann, L., Decker, K., Essers, M.A.G., Sinn, H.P., Spaich, S., et al. (2020). Metastasis-initiating cells induce and exploit a fibroblast niche to fuel malignant colonization of the lungs. Nat Commun 11: 1494.

Perez-Boza, J., Lion, M., and Struman, I. (2018). Exploring the RNA landscape of endothelial exosomes. RNA 24: 423-435.

Ramachandran, S., and Palanisamy, V. (2012). Horizontal transfer of RNAs: exosomes as mediators of intercellular communication. Wiley Interdiscip Rev RNA 3: 286-293. 
Raulf, N., Lucarelli, P., Thavaraj, S., Brown, S., Vicencio, J.M., Sauter, T., and Tavassoli, M. (2018). Annexin A1 regulates EGFR activity and alters EGFR-containing tumour-derived exosomes in head and neck cancers. Eur J Cancer 102: 52-68.

Reichert, D., Scheinpflug, J., Karbanova, J., Freund, D., Bornhauser, M., and Corbeil, D. (2016). Tunneling nanotubes mediate the transfer of stem cell marker CD133 between hematopoietic progenitor cells. Exp Hematol 44: 1092-1112 e1092.

Roberts, K.L., Manicassamy, B., and Lamb, R.A. (2015). Influenza A virus uses intercellular connections to spread to neighboring cells. J Virol 89: 1537-1549.

Roehlecke, C., and Schmidt, M.H.H. (2020). Tunneling nanotubes and tumor microtubes in cancer. Cancers 12: 857-857.

Rustom, A., Saffrich, R., Markovic, I., Walther, P., and Gerdes, H.H. (2004). Nanotubular highways for intercellular organelle transport. Science 303: 1007-1010.

Sahin, U., Kariko, K., and Tureci, O. (2014). mRNA-based therapeutics--developing a new class of drugs. Nat Rev Drug Discov 13: 759-780.

Sarantopoulou, D., Tang, S.Y., Ricciotti, E., Lahens, N.F., Lekkas, D., Schug, J., Guo, X.S., Paschos, G.K., FitzGerald, G.A., Pack, A.I., et al. (2019). Comparative evaluation of RNA-Seq library preparation methods for strand-specificity and low input. Sci Rep 9: 13477.

Sartori-Rupp, A., Cordero Cervantes, D., Pepe, A., Gousset, K., Delage, E., Corroyer-Dulmont, S., Schmitt, C., Krijnse-Locker, J., and Zurzolo, C. (2019). Correlative cryo-electron microscopy reveals the structure of TNTs in neuronal cells. Nat Commun 10: 342.

Schindelin, J., Arganda-Carreras, I., Frise, E., Kaynig, V., Longair, M., Pietzsch, T., Preibisch, S., Rueden, C., Saalfeld, S., Schmid, B., et al. (2012). Fiji: an open-source platform for biological-image analysis. Nat Methods 9: 676-682.

Sebastian, A., Hum, N.R., Martin, K.A., Gilmore, S.F., Peran, I., Byers, S.W., Wheeler, E.K., Coleman, M.A., and Loots, G.G. (2020). Single-Cell Transcriptomic Analysis of Tumor-Derived Fibroblasts and Normal TissueResident Fibroblasts Reveals Fibroblast Heterogeneity in Breast Cancer. Cancers (Basel) 12: 1307.

Segel, M., Lash, B., Song, J., Ladha, A., Liu, C.C., Jin, X., Mekhedov, S.L., Macrae, R.K., Koonin, E.V., and Zhang, F. (2021). Mammalian retrovirus-like protein PEG10 packages its own mRNA and can be pseudotyped for mRNA delivery. Science 373: 882-889. 
Singer, M., Wang, C., Cong, L., Marjanovic, N.D., Kowalczyk, M.S., Zhang, H., Nyman, J., Sakuishi, K., Kurtulus, S., Gennert, D., et al. (2016). A Distinct Gene Module for Dysfunction Uncoupled from Activation in TumorInfiltrating T Cells. Cell 166: 1500-1511 e1509.

Slobodin, B., and Dikstein, R. (2020). So close, no matter how far: multiple paths connecting transcription to mRNA translation in eukaryotes. EMBO Rep 21: e50799.

Stelzer, G., Rosen, N., Plaschkes, I., Zimmerman, S., Twik, M., Fishilevich, S., Stein, T.I., Nudel, R., Lieder, I., Mazor, Y., et al. (2016). The GeneCards Suite: From Gene Data Mining to Disease Genome Sequence Analyses. Curr Protoc Bioinformatics 54: 1.30.31-31.30.33.

Su, Q., and Igyarto, B.Z. (2019). Keratinocytes Share Gene Expression Fingerprint with Epidermal Langerhans Cells via mRNA Transfer. J Invest Dermatol 139: 2313-2323

Sun, Z., Asmann, Y.W., Nair, A., Zhang, Y., Wang, L., Kalari, K.R., Bhagwate, A.V., Baker, T.R., Carr, J.M., Kocher, J.P., et al. (2013). Impact of library preparation on downstream analysis and interpretation of RNASeq data: comparison between Illumina PolyA and NuGEN Ovation protocol. PLoS One 8: e71745.

Tang, X., Zhang, S., Fu, R., Zhang, L., Huang, K., Peng, H., Dai, L., and Chen, Q. (2019). Therapeutic Prospects of mRNA-Based Gene Therapy for Glioblastoma. Front Oncol 9: 1208.

Thakore, P.I., D'Ippolito, A.M., Song, L., Safi, A., Shivakumar, N.K., Kabadi, A.M., Reddy, T.E., Crawford, G.E., and Gersbach, C.A. (2015). Highly specific epigenome editing by CRISPR-Cas9 repressors for silencing of distal regulatory elements. Nat Methods 12: 1143-1149.

Tiwari, V., Koganti, R., Russell, G., Sharma, A., and Shukla, D. (2021). Role of Tunneling Nanotubes in Viral Infection, Neurodegenerative Disease, and Cancer. Front Immunol 12: 680891.

Torre, E., Dueck, H., Shaffer, S., Gospocic, J., Gupte, R., Bonasio, R., Kim, J., Murray, J., and Raj, A. (2018). Rare Cell Detection by Single-Cell RNA Sequencing as Guided by Single-Molecule RNA FISH. Cell Syst 6: 171179.

Trcek, T., and Singer, R.H. (2010). The cytoplasmic fate of an mRNP is determined cotranscriptionally: exception or rule? Genes Dev 24: 1827-1831.

Tsanov, N., Samacoits, A., Chouaib, R., Traboulsi, A.M., Gostan, T., Weber, C., Zimmer, C., Zibara, K., Walter, T., Peter, M., et al. (2016). smiFISH and FISH-quant - a flexible single RNA detection approach with superresolution capability. Nucleic Acids Res 44: e165.

Uhlén, M., Fagerberg, L., Hallström, B.M., Lindskog, C., Oksvold, P., Mardinoglu, A., Sivertsson, Å., Kampf, C., Sjöstedt, E., Asplund, A., et al. (2015). Tissue-based map of the human proteome. Science 347: 1260419. 
Valadi, H., Ekstrom, K., Bossios, A., Sjostrand, M., Lee, J.J., and Lotvall, J.O. (2007). Exosome-mediated transfer of mRNAs and microRNAs is a novel mechanism of genetic exchange between cells. Nat Cell Bio/ 9: 654-659.

van den Ent, F., and Lowe, J. (2006). RF cloning: a restriction-free method for inserting target genes into plasmids. J Biochem Biophys Methods 67: 67-74.

Van Hoecke, L., and Roose, K. (2019). How mRNA therapeutics are entering the monoclonal antibody field. J Transl Med 17: 54.

Villarroya-Beltri, C., Gutierrez-Vazquez, C., Sanchez-Madrid, F., and Mittelbrunn, M. (2013). Analysis of microRNA and protein transfer by exosomes during an immune synapse. Methods Mol Biol 1024: 41-51.

Wang, Y., Cui, J., Sun, X., and Zhang, Y. (2011). Tunneling-nanotube development in astrocytes depends on p53 activation. Cell Death Differ 18: 732-742.

Weng, Y., Li, C., Yang, T., Hu, B., Zhang, M., Guo, S., Xiao, H., Liang, X.J., and Huang, Y. (2020). The challenge and prospect of mRNA therapeutics landscape. Biotechnol Adv 40: 107534.

Wu, G., and Haw, R. (2017). Functional Interaction Network Construction and Analysis for Disease Discovery. Methods Mol Biol 1558: 235-253.

Xia, C., Babcock, H.P., Moffitt, J.R., and Zhuang, X. (2019). Multiplexed detection of RNA using MERFISH and branched DNA amplification. Sci Rep 9: 7721.

Yang, L., Perrera, V., Saplaoura, E., Apelt, F., Bahin, M., Kramdi, A., Olas, J., Mueller-Roeber, B., Sokolowska, E., Zhang, W., et al. (2019). m(5)C Methylation Guides Systemic Transport of Messenger RNA over Graft Junctions in Plants. Curr Biol 29: 2465-2476.

Yu, M., Guo, G., Huang, L., Deng, L., Chang, C.S., Achyut, B.R., Canning, M., Xu, N., Arbab, A.S., Bollag, R.J., et al. (2020). CD73 on cancer-associated fibroblasts enhanced by the A2B-mediated feedforward circuit enforces an immune checkpoint. Nat Commun 11: 515.

Zhang, C., Maruggi, G., Shan, H., and Li, J. (2019a). Advances in mRNA Vaccines for Infectious Diseases. Front Immunol 10: 594.

Zhang, W., Thieme, C.J., Kollwig, G., Apelt, F., Yang, L., Winter, N., Andresen, N., Walther, D., and Kragler, F. (2016). tRNA-Related Sequences Trigger Systemic mRNA Transport in Plants. Plant Cell 28: 1237-1249.

Zhang, Y., Cai, F., Liu, J., Chang, H., Liu, L., Yang, A., and Liu, X. (2018). Transfer RNA-derived fragments as potential exosome tRNA-derived fragment biomarkers for osteoporosis. Int J Rheum Dis 21: 1659-1669. 
Zhang, Y., Liu, Y., Liu, H., and Tang, W.H. (2019b). Exosomes: biogenesis, biologic function and clinical potential. Cell Biosci 9: 19.

Zhao, S., Zhang, Y., Gordon, W., Quan, J., Xi, H., Du, S., von Schack, D., and Zhang, B. (2015). Comparison of stranded and non-stranded RNA-seq transcriptome profiling and investigation of gene overlap. BMC Genomics 16: 675.

Zhu, C., Shi, Y., and You, J. (2021). Immune Cell Connection by Tunneling Nanotubes: The Impact of Intercellular Cross-Talk on the Immune Response and Its Therapeutic Applications. Mol Pharm 18: 772-786.

Zou, X., Hou, Y., Xu, J., Zhong, L., Zhou, J., Zhang, G., and Sun, J. (2020). Mitochondria transfer via tunneling nanotubes is an important mechanism by which CD133+ scattered tubular cells eliminate hypoxic tubular cell injury. Biochem Biophys Res Commun 522: 205-212.

Zuckerman, B., Ron, M., Mikl, M., Segal, E., and Ulitsky, I. (2020). Gene Architecture and Sequence Composition Underpin Selective Dependency of Nuclear Export of Long RNAs on NXF1 and the TREX Complex. Mol Cell 79: 251-267. 


\section{Figure legends:}

Figure 1. Affinity purification of single populations of MCF7 and MEF cells following mix/coculture

A. Schematic representation of the magnetic bead-based sorting and RNA sequencing to identify mRNAs transferred between two cell types. Between 2-3 million each of human and mouse cells (i.e. MCF7 cells and MBS-MEFs, respectively) are either co-cultured or only mixed before cell sorting. The heterologous cell population is then sorted using magnetic microbeads conjugated to an anti-CD326 antibody specific to MCF7 cells. The sorted cells are then analyzed by RNAsequencing to identify the transferred RNAs.

B. Flow cytometry profiles of the sorted cell populations of MCF7 and MBS-MEF cells following affinity purification. Post-sorting, cell suspensions were counterstained with a human CD326-Alexa 488 antibody that labels only the MCF7 cells and a mouse CD321-PE antibody that labels the MBSMEF cells. The sorted cell populations were analyzed by flow cytometry using the Alexa Fluor-488 and R-PE windows.

C-D. RT-PCR (C) and RT-qPCR (D) validation of transfer of $\beta$-actin mRNA from MCF7 to MBS-MEF cells in co-culture. Total RNA from one replicate of a MBS-MEF and MCF7 single culture and two replicates of MBS-MEF fractions from Mix and Co-culture were collected for analysis by semiquantitative RT-PCR (25 cycles) (C) and RT-qPCR (D) using primers specific for human $\beta$-actin. 18S rRNA was amplified as an internal control. * $-p \leq 0.05$.

Figure 2. Analysis of human RNAs present in mouse-enriched fractions and identification of transferred mRNAs.

A. Heat map analysis showing the transferred human RNA in mouse samples. RPM counts of human-specific genes across single culture, mix and co-culture samples of mouse-enriched fractions were Z-normalized across rows and plotted using the G-Plot package of R. Each row indicates a single gene and each column represents a sample. Cluster analysis of the samples was done by "maximum" distance function. 
B. PCA analysis of the different samples. Human-specific reads from mouse samples were analyzed and plotted, as a Principal Component Analysis graph using the base functions of R. Red icon: Coculture, Blue icon: Single Culture and Green icon: Mix).

C. Read distribution between the Co-culture and Mix samples. The lognormal distribution of the reads in Co-culture (purple bars) and Mix (orange bars) were plotted and fitted to a Gaussian curve, and revealing that mRNAs from almost the entire human trancriptome underwent transfer. This was depicted by a shift of the "Co-culture" curve to the right. The red bars represents the overlap between the two distributions. The $p$ value for the average of all human genes in the Gaussian is given.

D. Identification of RNAs that underwent robust transfer. A dot plot representing the results from a single-tailed, unpaired $t$-test between the two replicates of Co-culture and two replicates of Mix was performed to identify the genes exhibiting the highest transfer. Significance threshold (dashed line): Fold change $\geq 2$; false discovery rate $(F D R)<0.05$. Closed circles: Significant genes, open circles: Statistically insignificant genes. An FDR of 0.05 roughly implies that $5 \%$ of significant tests will result in false positives.

E-G. Identification of human RNAs in mouse cells relative to gene expression levels. Linear regression analyses of human-specific read counts from the mouse fraction of the Co-culture samples with respect to the human reads from mouse fraction of Mix samples (E) with the reads from the MCF7 Single culture (F), or with reads from MCF7 in co-culture (G), which provide various ways to look at the level of endogenous expression. The red line indicates the linear regression line, while the blue lines indicate the upper and lower bounds of the $99 \%$ confidence internal. Pearson and Spearman coefficients are indicated.

\section{Figure 3. Analysis of the percentage of human RNA transferred to mouse cells}

A. Genome wide distribution of proportion of donor mRNAs that undergo transfer. The black curve indicates the best-fit Gaussian distribution. Log of median percent transfer is indicated.

B. Linear regression analysis of the percentage transfer for each gene with the donor endogenous level of expression. Each circle represents an individual. Pearson correlation is indicated. 
C. Linear regression analysis of the percentage transfer of each mRNA with its half-life. Stability data of each mRNA was derived from a recent analysis of genome-wide mRNA half-lives (Blumberg et al., 2021). RPM count of transferred mRNAs (y-axis) and half-lives of mRNAs (x-axis) of 4972 annotated genes are plotted. Solid dark purple dots indicate 223 of the 283 robustly transferred mRNAs identified in Figure 2D and Supplementary Data File 1 - Table 3. The purple solid line indicates the linear regression line; Pearson coefficient is indicated.

D. Breast cancer-specific overexpressed and mutated genes were found to undergo mRNA transfer from MCF7 cells to MEFs. This list of human-mapped genes in mouse enriched fraction from coculture sample was compared to a set of 73 genes that were found to be overexpressed in 184 breast cancer samples from 11 patients, compared to 8 samples from healthy tissues (Axelsen et al., 2007) and to a set of 93 genes that were found to be frequently mutated in 560 breast cancer samples (Nik-Zainal et al., 2016). A representative list of genes from the indicated overlaps are mentioned in the boxes. Only the genes with RPM counts of $>10$ in both replicates of co-culture and FC>1 were considered for this analysis (7500 genes)

\section{Figure 4. PCR and smFISH verification of transfer of selected mRNAs.}

A. Heatmap summarizing transfer of human mRNAs in Co-culture compared to Mix. qRT-PCR was performed on RNA samples from MBS-MEF Single culture, Mix, and Co-culture samples from two independent biological replicates and the presence of transferred RNA was detected with humanspecific oligos for ten transferred genes, as identified in Figure 2D. Four less transferred genes were used as negative controls. Human $\beta$-actin was used as a positive control. The color of the heatmap corresponds to the row-wise Z-scores of $\mathrm{Ct}$ values of the indicated genes after normalizing for an internal control (18S rRNA). Increasing darkness corresponds to increasing gene expression. All but one gene (i.e. GNAS) showed good agreement with the RNA-seq results and have a higher fold-change as compared to the Mix sample. Each box represents an average of three independent technical replicates.

B-C. Verification by smFISH. Three genes (KRT8, PSAP and CCND1) that demonstrated high level of transfer by RNA-Seq were chosen to be analysed by smFISH. Acceptor cells (MBS-MEFs) were co-cultured with MCF7 cells together on fibronectin-coated coverslips at a ratio of 1:1 for 12 hours. 
Following co-culture, the cells were fixed and smFISH was performed using Quasar 570-labeled oligonucleotide probes complementary to the human-specific RNA of the indicated genes and Cy5labeled probes specific for the MBS sequence. The transfer of mRNAs was detected by wide-field microscopy and quantified using a MATLAB program, FISH-Quant. (B) smFISH images. Representative smFISH images of MBS-MEF and MCF7 single cultures, and MCF7 cells in co-culture with MBS-MEFs. Labels: gray, Q570-labeled smFISH probes; blue, DAPI staining of the nucleus. Donor and acceptor cells were distinguished by the high expression of $\beta$-actin-MBS (identified by Cy5-MBS probes ) in MBS-MEF cells only (not shown). Scale bar: $10 \mu \mathrm{m}$. (C) Quantification of the number of mRNAs. The left panels show the number of mRNAs expressed for the indicated genes in the MCF7 cells only, while the right panel shows the number of corresponding mRNAs in MBSMEF cells alone or in co-culture. Each dot represents the number of indicated mRNAs detected in a single cell, as measured by FISH-Quant. Horizontal red lines represent the average number of mRNAs. $* *-p \leq 0.01 ; * * * *-p \leq 0.0001$.

\section{Figure 5. mRNA transfer is driven by gene expression}

A. tdTomato RNA smFISH images. Representative smFISH images of Cy5-labeled tdTomato RNA in WT MEFs and donor MBS-MEFs expressing either high or low levels of tdTomato in single cell culture (top row) and acceptor WT MEFs after co-culture (bottom row) are shown. White spots: Cy5 labeled tdTomato FISH. Blue: DAPI labeling. Dashed outlines represent the approximate cellular and nuclear boundaries. Donor and acceptor cells were differentiated by the number of spots and the presence of transcription sites, which appear only in donor cells.

B. Distribution of the tdTomato spots. FISH-Quant quantification of the number of tdTomato RNAs detected in each cell (denoted as a single dot) in donor MBS-MEFs cells (left) and WT MEF acceptor cells alone or in co-culture (right). Red horizontal line indicates the mean of the distribution. The samples in WT-MEF and in co-culture were compared by a one-way ANOVA, followed by indicated post-hoc pairwise comparisons. Expression in the two donor cell populations were compared by unpaired t-test. * - $\mathrm{p} \leq 0.05 ; * * * *-p \leq 0.0001$.

C. Use of a doxycycline-inducible tdTomato. MBS-MEFs stably expressing tdTomato under the control of a doxycycline-inducible promoter were incubated with increasing concentrations of 
doxycycline (0-4 $\mathrm{mg} / \mathrm{ml}$ ) for $24 \mathrm{hrs}$ prior to co-culture with WT MEFs in medium containing the same concentration of doxycycline. Left panel: Score of smFISH labeling of donor tdTomato MBSMEFs using probes against tdTomato RNA. Right panel: Score of smFISH labeling of tdTomato RNA in acceptor WT MEFs after co-culture. Expression (left panel) and RNA transfer (right panel) between untreated and doxycycline-treated cells, respectively, was compared using an unpaired t-test. Red horizontal line indicates the mean of the distribution. ${ }^{*}-p \leq 0.05 ; * *-p \leq 0.01 ; * * *$ $\mathrm{p} \leq 0.001 ; * * * *-\mathrm{p} \leq 0.0001$.

\section{Figure 6. Differential gene expression in acceptor cells in response to co-culture}

RPM counts from the mouse fraction of MBS-MEF Single culture, Mix, and Co-culture samples were aligned with the mouse reference genome $(\mathrm{mm} 10)$ and analysed further as follows.

A. Heatmap analysis indicating up-and down-regulated clusters of genes. Normalized read counts (RPM) of mouse-specific genes across Single culture, Mix, and Co-culture mouse samples were Znormalized across rows and plotted using G-Plot package of R. Each row indicates a single gene and each column represents a sample. Cluster analysis of the samples was done by "maximum" distance function and the top dendrogram shows the results.

B. PCA analysis of the samples: Mouse-specific reads from mouse samples were analyzed and plotted, as a Principal Component Analysis graph by using the base function of R. Red icon: Coculture, Blue icon: Single Culture and Green icon: Mix).

C. Volcano plot depicting differentially regulated genes and representative pathways: Mousealigned genes in two replicates of "Mix" and "Co-culture" were analyzed for differential gene regulation by Deseq2 package in $\mathrm{R}$ with default parameters. Results are shown as a volcano plot with the fold change in co-culture over mix and the corresponding adjusted p-values. Threshold limit for significance was set at $p=0.05$. Upregulated genes are shown in light green, while the downregulated genes are shown in pink. Gray dots represent statistically insignificant genes. Black dashed lines show the fold change threshold value of \pm 2 . Selected top upregulated and downregulated genes grouped by their cancer-related KEGG pathways are indicated.

Figure 7. Upregulation of CAF-associated genes in MEF acceptor cells in co-culture 
Fold changes of differentially regulated genes $\left(p_{a d j}<0.05\right)$ in MEFs in co-culture compared to MEF in Mix (Figure 6) were compared to fold changes of corresponding genes in EG7-tumour derived CAFs over their precursor Mesenchymal Stem Cells (MSC)(Yu et al., 2020). Each point represents a gene. Thirty genes (marked in purple) were found to be significantly upregulated in both studies while seventeen genes (marked in red) were found to be downregulated. Among the upregulated ones, several genes (listed in the table on the right) were found to be upregulated in metastatic lung cancer-derived CAFs(Pein et al., 2020). 


\section{Supplementary Figure Legends}

Supplementary Figure 1. Flow cytometry profiles of single cultures of MBS-MEF and MCF7 cells and bioinformatic pipeline to identify species-specific mRNAs

A. Three million MBS-MEF and MCF7 cells were each subjected separately to same sorting protocol (without undergoing mixing/co-culture with each other) as shown in Figure $1 \mathrm{~A}$ and used in Figure 1B. The flow cytometry profiles for the expression of mouse CD321 and human CD326 on MBSMEF and MCF7 cells, respectively, after sorting are shown.

B. A scheme depicting the identification of human (MCF7) mRNAs in mouse (MBS-MEF) cells. Following the trimming of adaptors and filtering for low-quality reads, the reads were aligned to human reference genomes. Reads that were paired-end and showed unique alignment with human genome were again realigned with mouse reference genome to discard genes with $100 \%$ homology. The resulting clean human reads were finally identified based on status of alignment of ends and mismatches with human and mouse genomes. For detailed explanation, see Materials and Methods.

\section{Supplementary Figure 2. Analysis of the fold-change (FC) of human RNA transferred to mouse} cells. Genome-wide distribution of fold-change (i.e. RPM of Coculture samples divided by RPM of Mix samples) of human mRNAs that undergo transfer vs. the endogenous level of expression in the donor MCF7 cells. Pearson correlation value is indicated.

Supplementary Figure 3. GO annotation and pathway analysis of the highly transferred genes. The list of 283 highly transferred genes was analyzed by DAVID (Database for Annotation, Visualization and Integrated Discovery) and GeneCards for GO annotations and by Reactome and KEGG for pathway analysis. Shown are the top 20 terms for each GO terms family (A) Biological processes, (B) Molecular Function and (C) Cellular Component along with their log (adjusted P values). (D) The top 20 enriched KEGG pathways and the number of genes in the corresponding pathway.

Supplementary Figure 4. No cis element is involved in $\beta$-actin mRNA transfer 
A. Schematic of the construct design: The CDS and 3' UTR of the $\beta$-actin were divided into five segments, namely $C D 1, C D 2, C D 3,3 U 1,3 \cup 2$. The three fragments of coding sequences were designed to be overlapping so as to detect any cis element that might occur in the junction. The $3^{\prime}$ UTR was divided at the bp 441 after the stop codon as the insertion of MBS at this point was used to detect robust transfer, as reported previously(Haimovich et al., 2017). Each of the constructs was cloned after the stop codon of tdTomato CDS and under the control of a constitutely active Ubiquitin promoter. A construct using just the tdTomato CDS and no $\beta$-actin fragment was used as a control. Transfer of each construct was followed by smFISH for the tdTomato CDS.

B. smFISH images: Representative images of Cy5-labeled tdTomato RNA by smFISH in donor cells (top row), acceptor cells (last column) and acceptor cells in culture with donor cells expressing six different constructs (middle row). Indicated squares are magnified, with the transferred RNAs indicated by arrowheads. Gray: Cy5 labelled tdTomato FISH spots. Blue: DAPI. Dashed outline represent the approximate cell boundary. Scale bar: $10 \mu \mathrm{m}$

C. Distribution of the tdTomato spots: FISH-Quant quantification of the number of tdTomato mRNAs detected (each cell is a single dot) in donor cells (left) and acceptor cells alone or in coculture (right). The red horizontal lines indicate the mean of the distribution. The samples were statistically compared by a one-way ANOVA, followed by post hoc pairwise comparisons, details of which are given in Table 2.

\section{Supplementary Figure 5. MEME analysis of transferred genes}

A. Consensus motifs of the genes encoding top-most transferred RNAs. Different consensus motifs were identified among the top-most 279 transferred RNAs, as analyzed using MEME Suite. \# indicates the number of query genes bearing the motif. The motifs are arranged from top to bottom according to decreasing statistical significance. B. Consensus motifs identified among the least-transferred genes are shown. For comparison to $A$, three different groups of $\sim 300$ genes each of the least transferred mRNAs were analyzed and displayed in the same fashion. Set $1=300$ genes examined; Set 2 = 288; Set $3=299$.

\section{Supplementary Figure 6. Role of cell-cell contact in intercellular mRNA transfer}


A. Schematic of the conditioned media and quadrapod setup: (Top) Conditioned media was derived from a culture plate of MCF7 cells and transferred to a plate of MEF cells. (Bottom) In the quadrapod setup, MEF cells were cultured in a 15-cm plate while a disk with four Perspex legs ("quadrapod") was placed upside down. The disk contained an equivalent number of MCF7 cells, facing towards the MEF. MCF7 and MBS-MEF cells were separated by $\sim 2-3 \mathrm{~mm}$. Following culture, magnetic sorting and FACS validation, the transfer of candidate human genes in mouse cells was detected by qPCR using human-specific oligos.

B. Detection of transferred human genes in mouse samples: Transfer of 5 human mRNAs were compared in four experimental conditions - Co-culture, Mix, Quadrapod, and Conditioned Media, from two independent biological replicates. Each row represents a gene while each column represents an experimental condition. The color in each box represents the $\mathrm{Z}$ scores of the $\mathrm{Ct}$ values after normalizing for an endogenous control (18S) and corresponding donor cell expression. Darker colors correspond to higher transfer.

\section{Supplementary Figure 7. Analysis of differentially expressed genes in acceptor MEFs after co- culture}

A-B. GO analysis of the differentially expressed genes in acceptor cells. The list of statistically significant upregulated and downregulated genes with a fold change of $\geq \pm 2$ and were analysed by DAVID (Database for Annotation, Visualization and Integrated Discovery) and GeneCards for GO annotations. The top ten annotations corresponding to molecular functions, cellular components and biological processes for upregulated (A) and downregulated (B) are shown, along with the adjusted $P$ values.

C-D. Pathway analysis of the differentially expressed genes in acceptor cells. The list of statistically significant upregulated and downregulated genes from the DESeq2 analysis were analysed for enriched pathways using the KEGG (Kyoto Encyclopedia of Genes and Genomes) database. Top ten upregulated $(C)$ and downregulated pathways (D) are shown along with the adjusted $P$ values. 


\section{Tables}

Table 1. Percentage of cell separation after antigen-based magnetic bead cell sorting

\begin{tabular}{|l|l|l|l|l|}
\hline Sample & \% MCF7 $^{\mathbf{1}}$ & $\begin{array}{l}\text { \% False } \\
\text { positive }\end{array}$ & \% MBS-MEF & $\begin{array}{l}\text { \% Un- } \\
\text { stained }^{\mathbf{4}}\end{array}$ \\
\hline MCF7 Single culture Replicate 1 & 99.70 & 0.30 & 0 & 0 \\
\hline MCF7 Single culture Replicate 2 & 99.58 & 0.42 & 0 & 0 \\
\hline MBS-MEF Single culture Replicate 1 & 0 & 0.04 & 99.84 & 0.12 \\
\hline MBS-MEF Single culture Replicate 1 & 0 & 0.03 & 99.86 & 0.11 \\
\hline $\begin{array}{l}\text { MCF7 cells enriched from Mix Replicate 1 } \\
\text { MCF7 cells enriched from Mix Replicate 2 }\end{array}$ & 99.57 & 0.10 & 0.27 & 0.06 \\
\hline $\begin{array}{l}\text { MCF7 cells enriched from Co-culture } \\
\text { Replicate 1 }\end{array}$ & 99.74 & 0.21 & 0.17 & 0.05 \\
\hline $\begin{array}{l}\text { MCF7 cells enriched from Co-culture } \\
\text { Replicate 2 }\end{array}$ & 99.70 & 0.19 & 0.04 & 0.03 \\
\hline $\begin{array}{l}\text { MBS-MEF cells enriched from Mix Replicate } \\
1\end{array}$ & 0 & 0.08 & 97.10 & 2.82 \\
\hline $\begin{array}{l}\text { MBS-MEF cells enriched from Mix Replicate } \\
2\end{array}$ & 0.05 & 0.03 & 97.25 & 2.67 \\
\hline $\begin{array}{l}\text { MBS-MEF cells enriched from Co-culture } \\
\text { Replicate 1 }\end{array}$ & 0 & 0.03 & 98.96 & 1.01 \\
\hline $\begin{array}{l}\text { MBS-MEF cells enriched from Co-culture } \\
\text { Replicate 2 }\end{array}$ & 0 & 0 & 98.10 & 1.90 \\
\hline
\end{tabular}

$1 \%$ MCF7 cells are cells in the lower right quadrant (CD326 positive, CD321 negative)

$2 \%$ "Double stained" cells, most likely false-positive stained cells

3 \%MBS-MEFs cells are cells in the upper left quadrant (CD321 positive, CD326 negative)

$4 \%$ Unstained cells 
Table 2: Results from post-hoc Tukey Test following one way ANOVA from Supplementary Figure S4C - Detection of tdTomato mRNA transfer from donor MBS-MEFs expressing tdTomato- $\beta$-actin fusions to WT MEFs

\begin{tabular}{|c|c|c|c|c|c|}
\hline \multicolumn{6}{|c|}{ Donor cells } \\
\hline $\begin{array}{l}\text { Tukey's } \\
\text { multiple } \\
\text { comparisons } \\
\text { test }\end{array}$ & $\begin{array}{l}\text { Mean } \\
\text { diff. }\end{array}$ & $95.00 \% \mathrm{Cl}$ of diff. & $\begin{array}{l}\text { Below } \\
\text { threshold? }\end{array}$ & Summary & $\begin{array}{l}\text { Adjusted } \\
\text { p value }\end{array}$ \\
\hline $3 U 1$ vs. $3 U 2$ & -9.906 & -126.0 to 106.2 & No & ns & 0.9999 \\
\hline $3 U 1$ vs. $C D 1$ & 110 & -2.552 to 222.5 & No & ns & 0.0597 \\
\hline $3 U 1$ vs. CD2 & 130.8 & 12.67 to 249.0 & Yes & $*$ & 0.0202 \\
\hline $3 U 1$ vs. CD3 & 98.9 & -12.11 to 209.9 & No & ns & 0.1123 \\
\hline $\begin{array}{l}3 \mathrm{U} 1 \mathrm{vs} . \\
\text { tdTom }\end{array}$ & 97.98 & -16.59 to 212.5 & No & ns & 0.1425 \\
\hline $3 \cup 2$ vs. $C D 1$ & 119.9 & 3.804 to 236.0 & Yes & $*$ & 0.0383 \\
\hline $3 \cup 2$ vs. CD2 & 140.7 & 19.19 to 262.3 & Yes & $*$ & 0.0127 \\
\hline $3 \cup 2$ vs. CD3 & 108.8 & -5.802 to 223.4 & No & ns & 0.0739 \\
\hline $\begin{array}{l}3 \mathrm{U} 2 \mathrm{vs} . \\
\text { tdTom }\end{array}$ & 107.9 & -10.18 to 225.9 & No & ns & 0.0957 \\
\hline CD1 vs. CD2 & 20.86 & -97.31 to 139.0 & No & ns & 0.996 \\
\hline CD1 vs. CD3 & -11.08 & -122.1 to 99.93 & No & ns & 0.9997 \\
\hline $\begin{array}{l}\text { CD1 vs. } \\
\text { tdTom }\end{array}$ & -12 & -126.6 to 102.6 & No & ns & 0.9997 \\
\hline CD2 vs. CD3 & -31.94 & -148.7 to 84.78 & No & ns & 0.9704 \\
\hline $\begin{array}{l}\text { CD2 vs. } \\
\text { tdTom }\end{array}$ & -32.86 & -153.0 to 87.25 & No & ns & 0.9704 \\
\hline $\begin{array}{l}\text { CD3 vs. } \\
\text { tdTom }\end{array}$ & -0.9209 & -114.0 to 112.2 & No & ns & $>0.9999$ \\
\hline \multicolumn{6}{|c|}{ Acceptor cells and Acceptor cells in Coculture } \\
\hline WT vs. $3 U 1$ & -14.4 & -18.06 to -10.74 & Yes & $* * * *$ & $<0.0001$ \\
\hline WT vs. $3 \cup 2$ & -9.615 & -13.32 to -5.914 & Yes & $* * * *$ & $<0.0001$ \\
\hline WT vs. CD1 & -5.842 & -9.503 to -2.181 & Yes & $* * * *$ & $<0.0001$ \\
\hline WT vs. CD2 & -6.917 & -10.46 to -3.376 & Yes & $* * * *$ & $<0.0001$ \\
\hline WT vs. CD3 & -6.733 & -10.20 to -3.268 & Yes & $* * * *$ & $<0.0001$ \\
\hline $\begin{array}{l}\text { WT vs. } \\
\text { tdTom }\end{array}$ & -12.47 & -16.07 to -8.859 & Yes & $* * * *$ & $<0.0001$ \\
\hline $3 U 1$ vs. $3 U 2$ & 4.785 & 1.083 to 8.486 & Yes & $* *$ & 0.0027 \\
\hline $3 U 1$ vs. CD1 & 8.558 & 4.897 to 12.22 & Yes & $* * * *$ & $<0.0001$ \\
\hline $3 U 1$ vs. CD2 & 7.483 & 3.941 to 11.02 & Yes & $* * * *$ & $<0.0001$ \\
\hline $3 U 1$ vs. CD3 & 7.667 & 4.201 to 11.13 & Yes & $* * * *$ & $<0.0001$ \\
\hline
\end{tabular}


bioRxiv preprint doi: https://doi.org/10.1101/2021.11.28.470233; this version posted November 28, 2021. The copyright holder for this preprint (which was not certified by peer review) is the author/funder, who has granted bioRxiv a license to display the preprint in perpetuity. It is made available under aCC-BY-NC-ND 4.0 International license.

\begin{tabular}{|l|l|l|l|l|l|}
\hline $\begin{array}{l}\text { 3U1 vs. } \\
\text { tdTom }\end{array}$ & 1.935 & -1.672 to 5.541 & No & ns & 0.6913 \\
\hline 3U2 vs. CD1 & 3.773 & 0.07205 to 7.475 & Yes & $*$ & 0.0423 \\
\hline 3U2 vs. CD2 & 2.698 & -0.8851 to 6.281 & No & ns & 0.2825 \\
\hline 3U2 vs. CD3 & 2.882 & -0.6255 to 6.390 & No & ns & 0.1877 \\
\hline $\begin{array}{l}3 U 2 \text { vs. } \\
\text { tdTom }\end{array}$ & -2.85 & -6.497 to 0.7971 & No & ns & \\
\hline CD1 vs. CD2 & -1.075 & -4.617 to 2.466 & No & ns & 0.2402 \\
\hline CD1 vs. CD3 & -0.8912 & -4.357 to 2.574 & No & ns & 0.9885 \\
\hline $\begin{array}{l}\text { CD1 vs. } \\
\text { tdTom }\end{array}$ & -6.623 & -10.23 to -3.017 & Yes & $* * * *$ & $<0.0001$ \\
\hline CD2 vs. CD3 & 0.1841 & -3.155 to 3.523 & No & ns & $>0.9999$ \\
\hline $\begin{array}{l}\text { CD2 vs. } \\
\text { tdTom }\end{array}$ & -5.548 & -9.033 to -2.063 & Yes & $* * * *$ & $<0.0001$ \\
\hline $\begin{array}{l}\text { CD3 vs. } \\
\text { tdTom }\end{array}$ & -5.732 & -9.139 to -2.325 & Yes & $* * * *$ & $<0.0001$ \\
\hline
\end{tabular}

Mean diff: Differences between the means of two distributions

Cl: Confidence interval

ns: non-significant

$*$ adjusted $p$-value $<0.05$

$* *$ adjusted $p$-value $<0.005$

$* * * *$ adjusted $\mathrm{p}$-value $<0.0001$ 


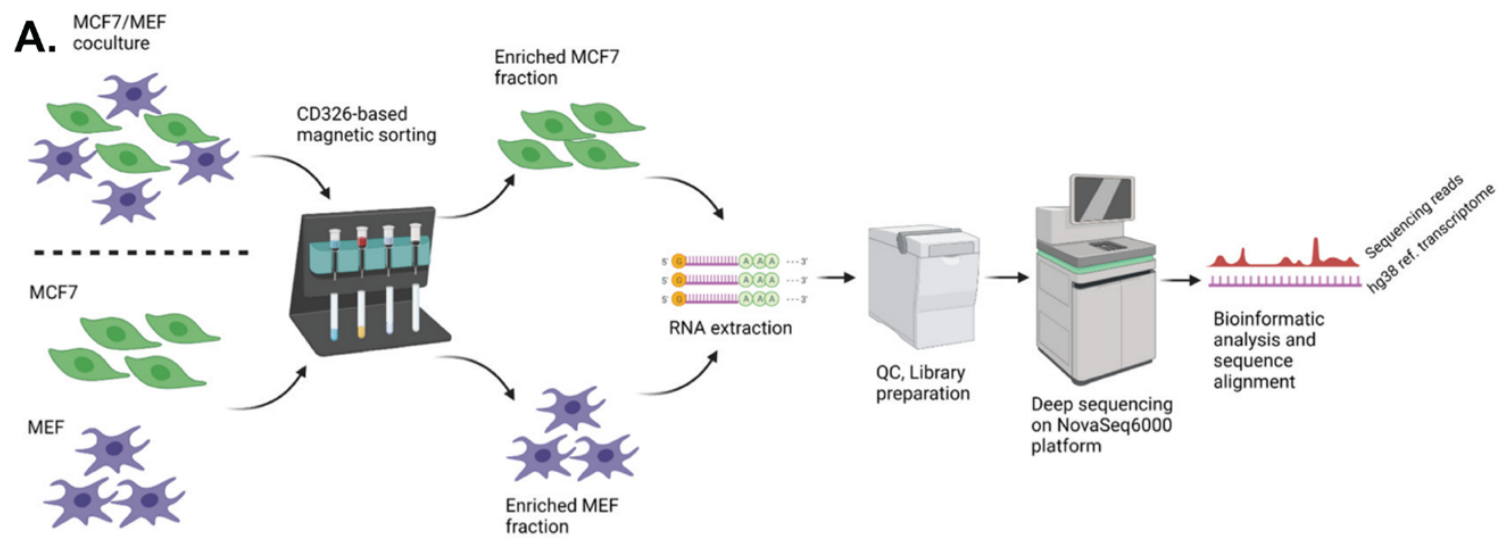

B.

Control: Mix

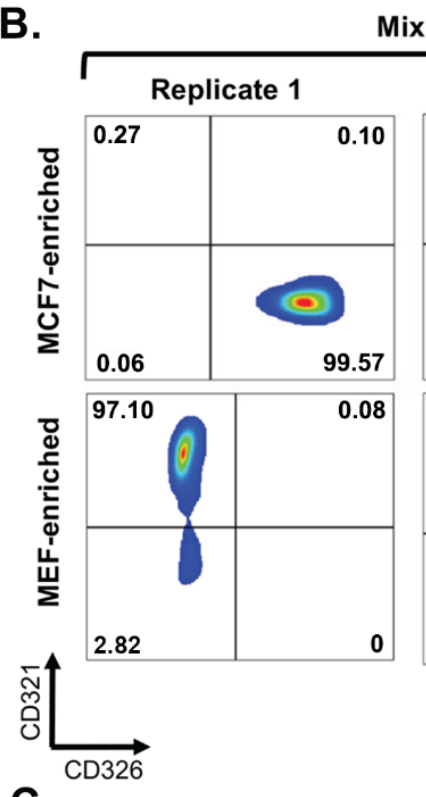

Mix

Co-culture

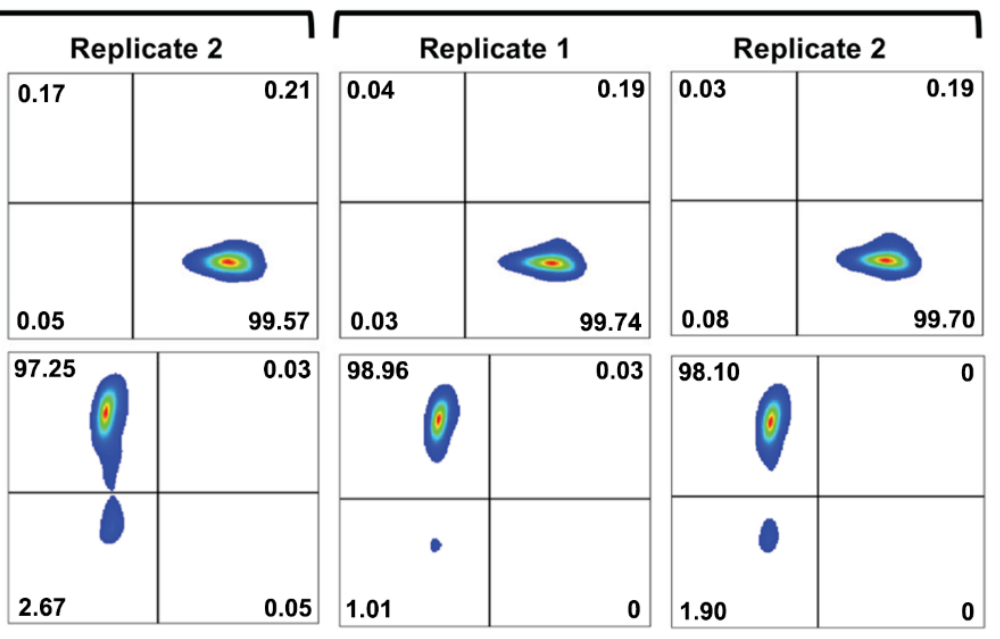

C.

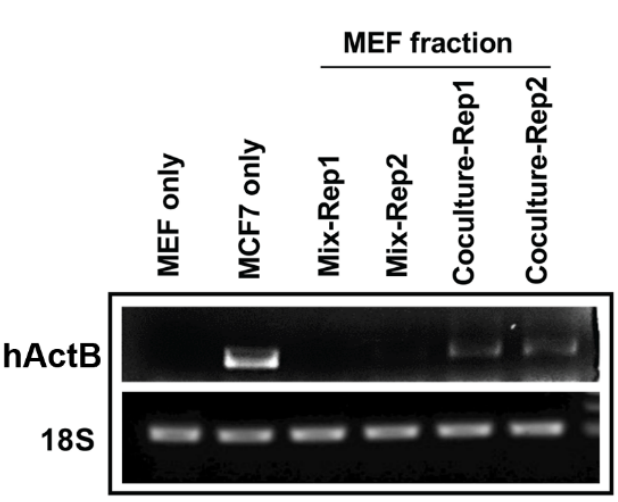

D.

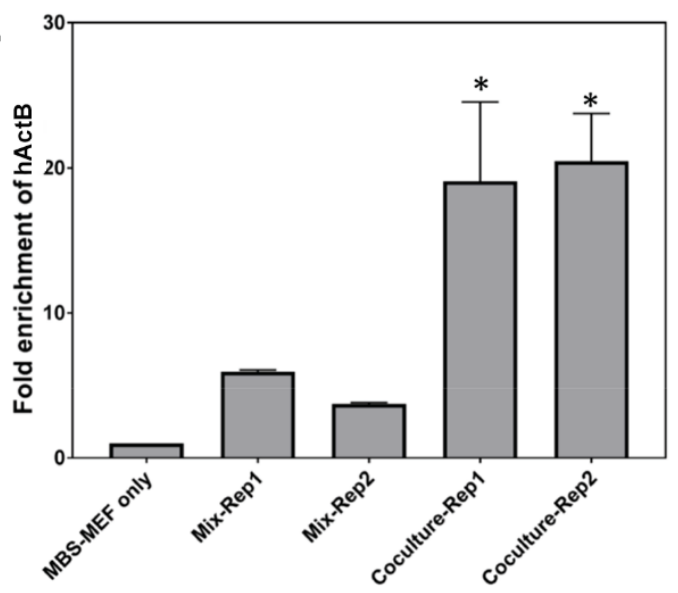

Figure 1. 
bioRxiv preprint doi: https://doi.org/10.1101/2021.11.28.470233; this version posted November 28, 2021. The copyright holder for this preprint (which was not certified by peer review) is the author/funder, who has granted bioRxiv a license to display the preprint in perpetuity. It is made available under aCC-BY-NC-ND 4.0 International license.
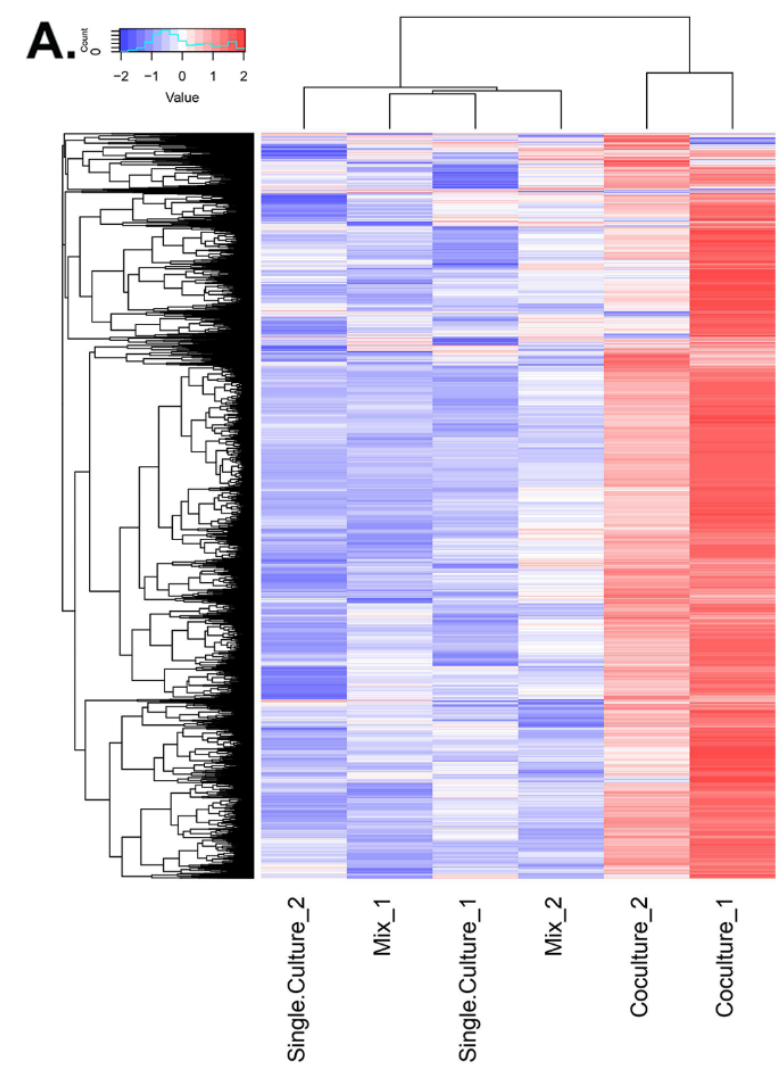

D.

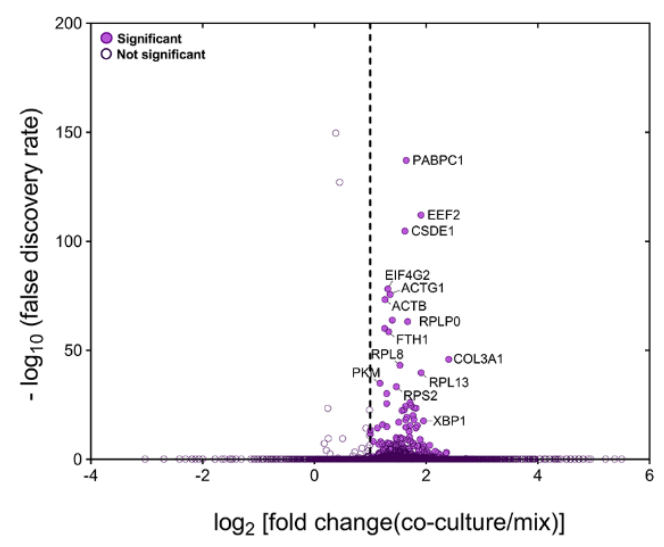

F.

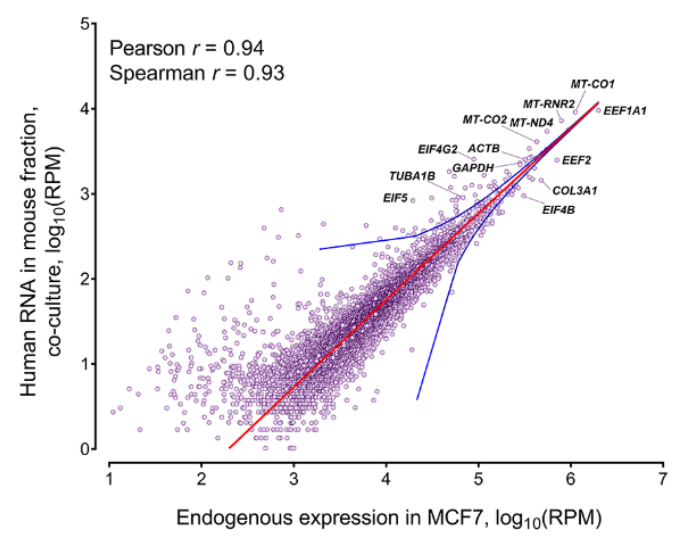

Figure 2
B.

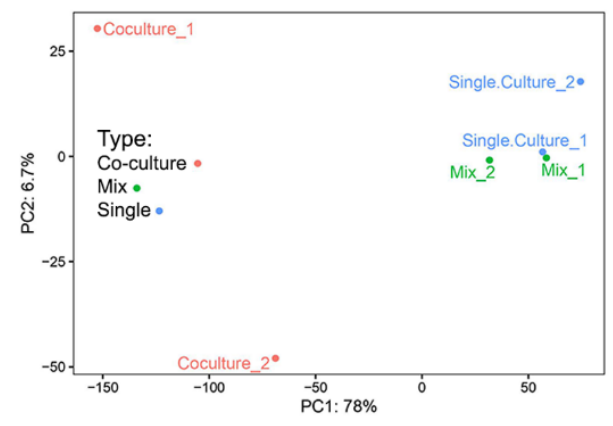

C.

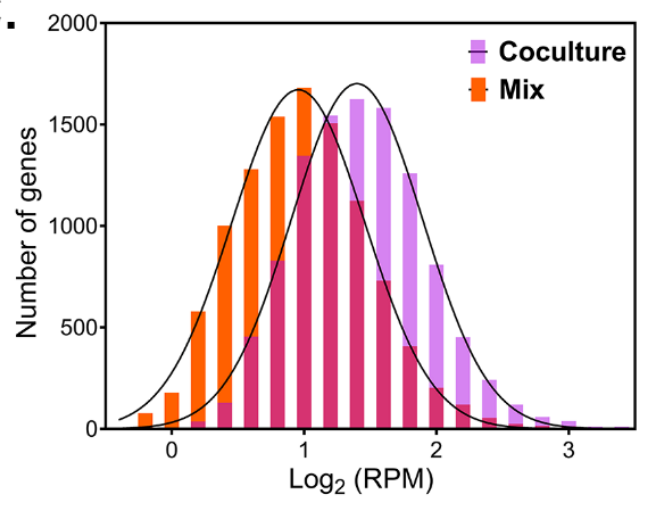

E.

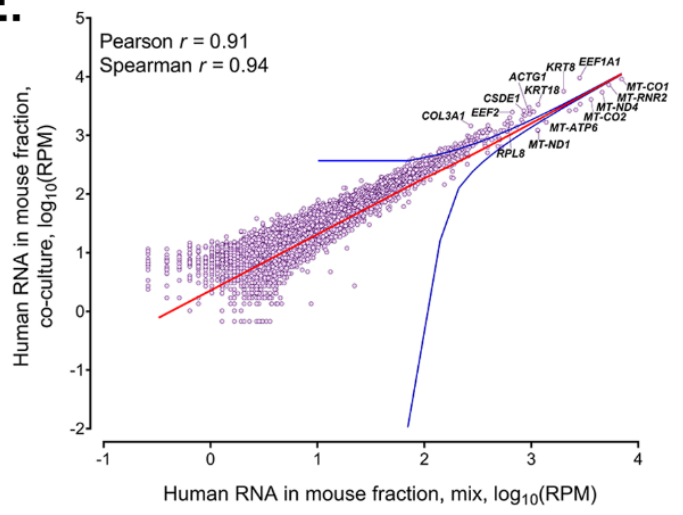

G.

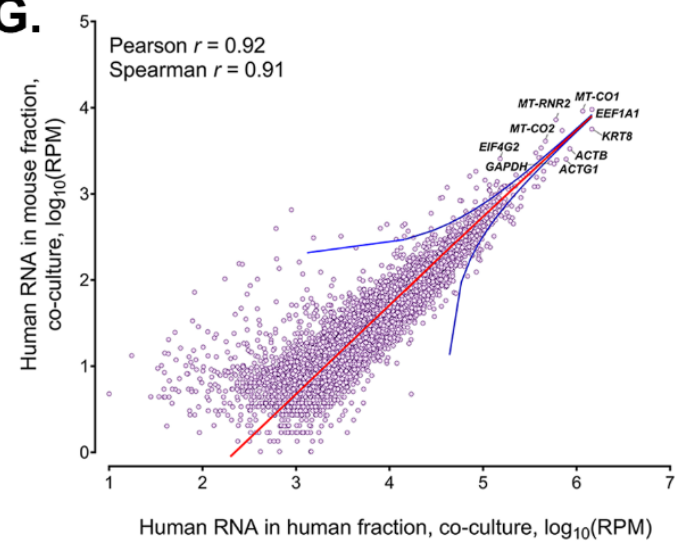


bioRxiv preprint doi: https://doi.org/10.1101/2021.11.28.470233; this version posted November 28, 2021. The copyright holder for this preprint (which was not certified by peer review) is the author/funder, who has granted bioRxiv a license to display the preprint in perpetuity. It is made available under aCC-BY-NC-ND 4.0 International license.

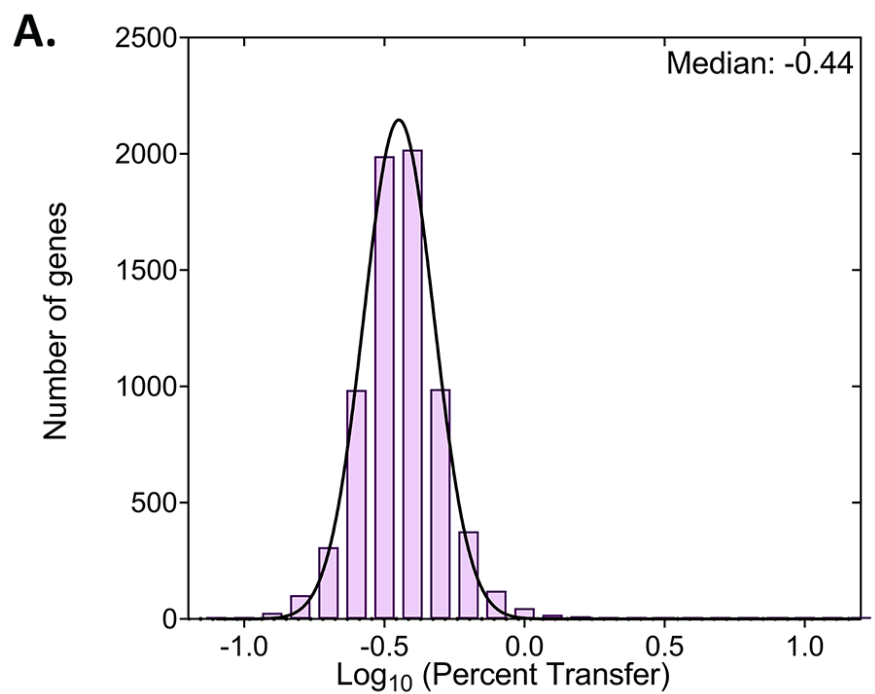

C.

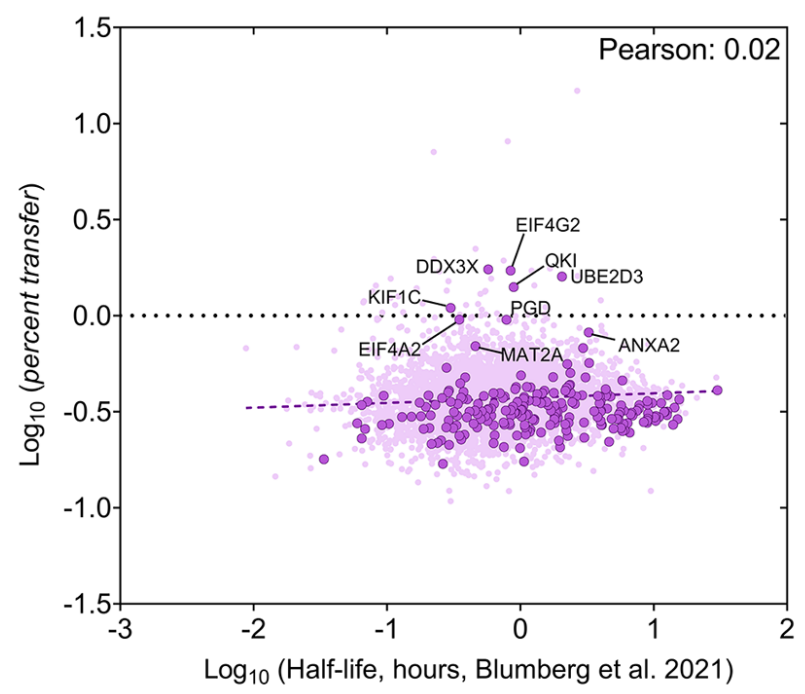

Figure 3
B.

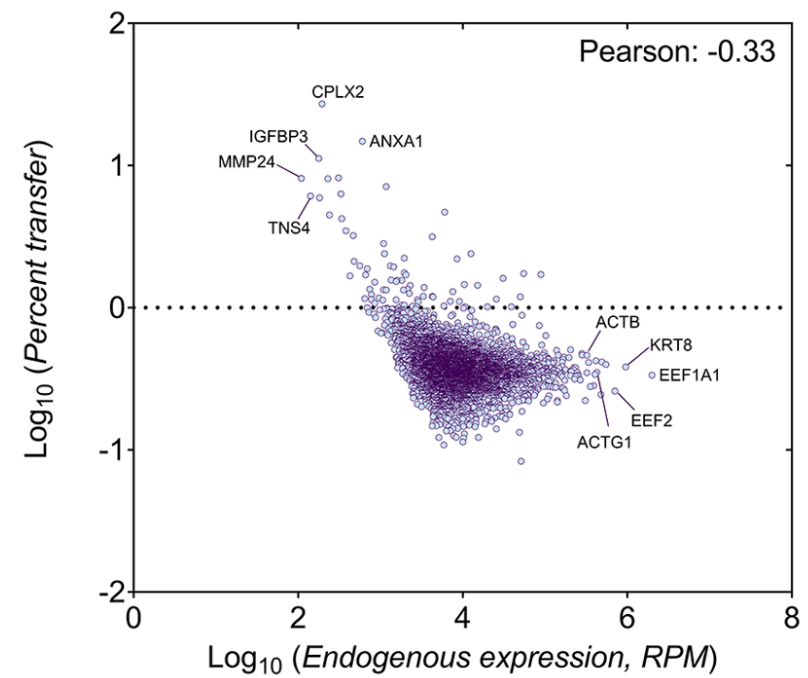

D.

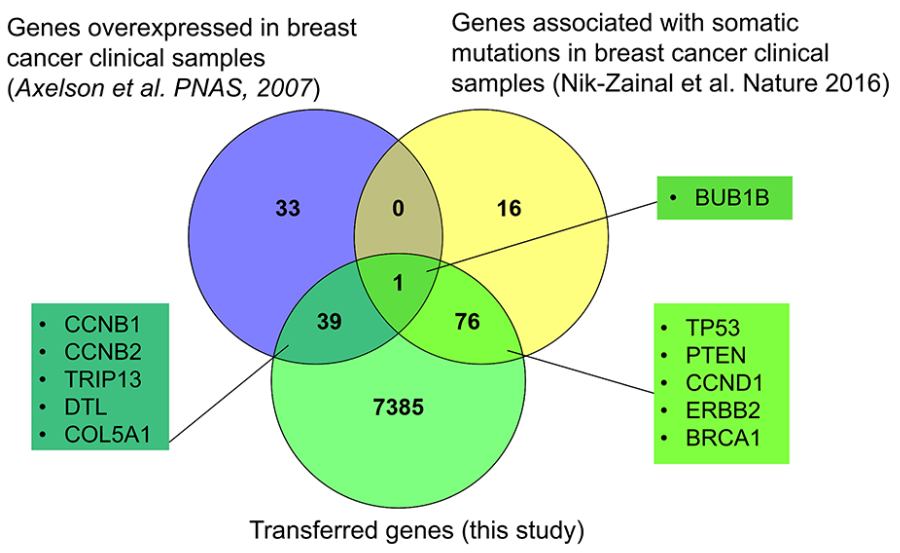


bioRxiv preprint doi: https://doi.org/10.1101/2021.11.28.470233; this version posted November 28, 2021. The copyright holder for this preprint (which was not certified by peer review) is the author/funder, who has granted bioRxiv a license to display the preprint in perpetuity. It is made available under aCC-BY-NC-ND 4.0 International license.

A.

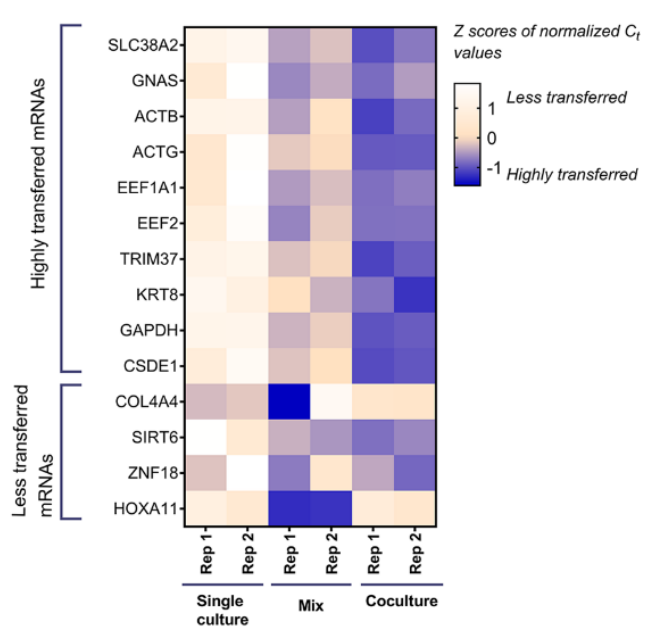

B

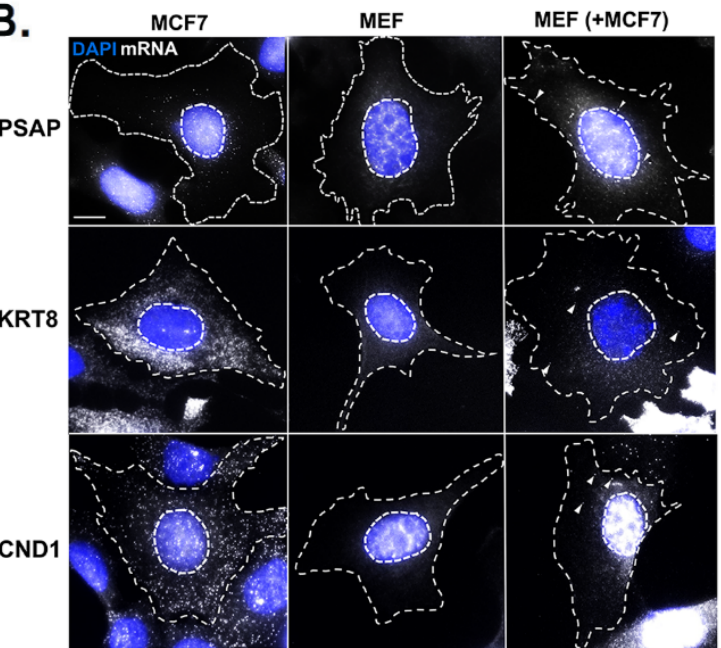

C.

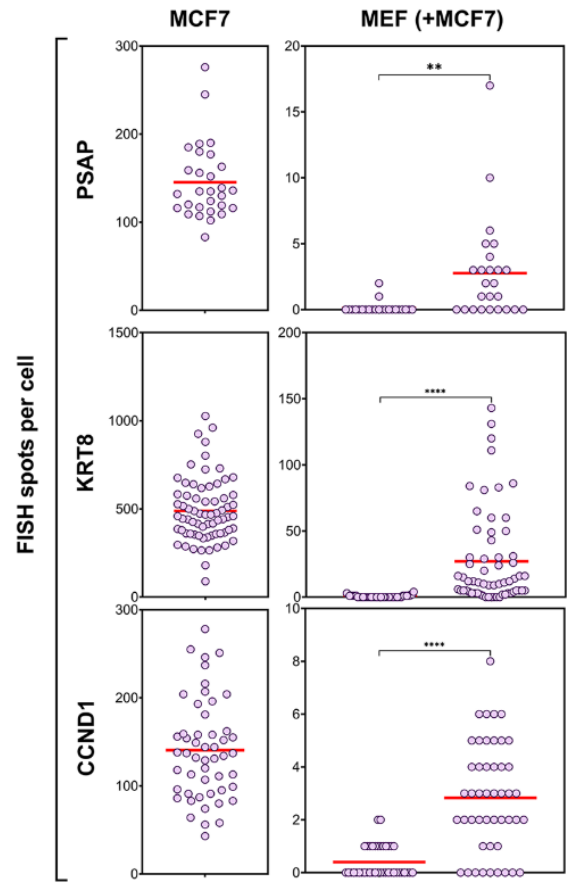

Figure 4 
bioRxiv preprint doi: https://doi.org/10.1101/2021.11.28.470233; this version posted November 28, 2021. The copyright holder for this preprint (which was not certified by peer review) is the author/funder, who has granted bioRxiv a license to display the preprint in perpetuity. It is made available under aCC-BY-NC-ND 4.0 International license.

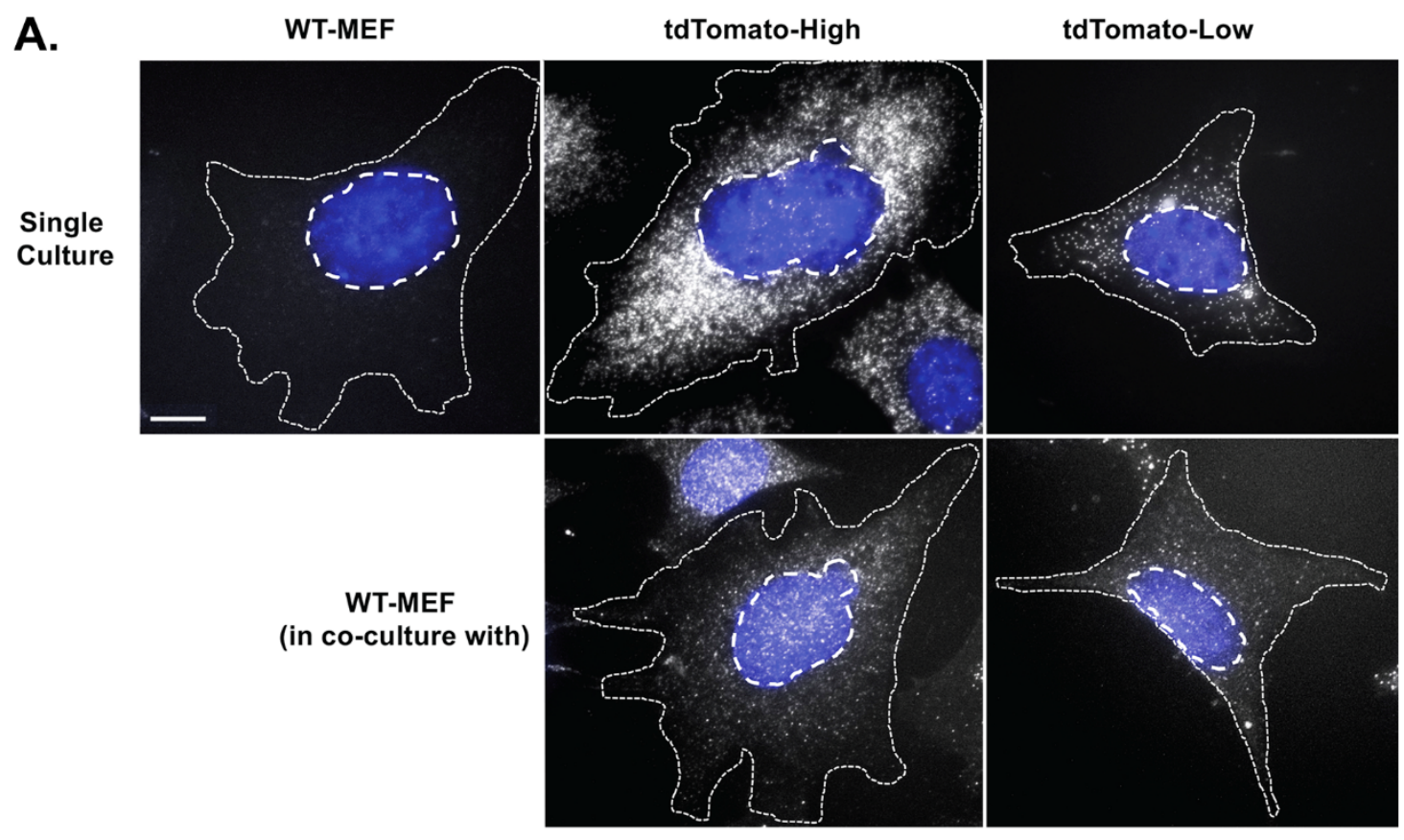

B.
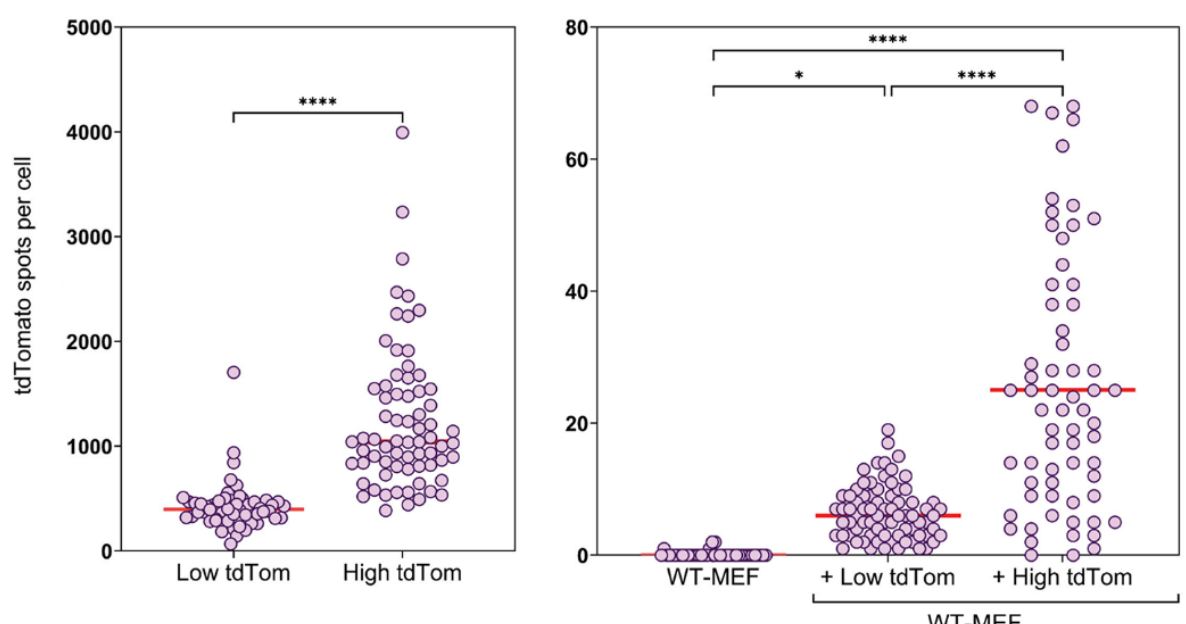

c.
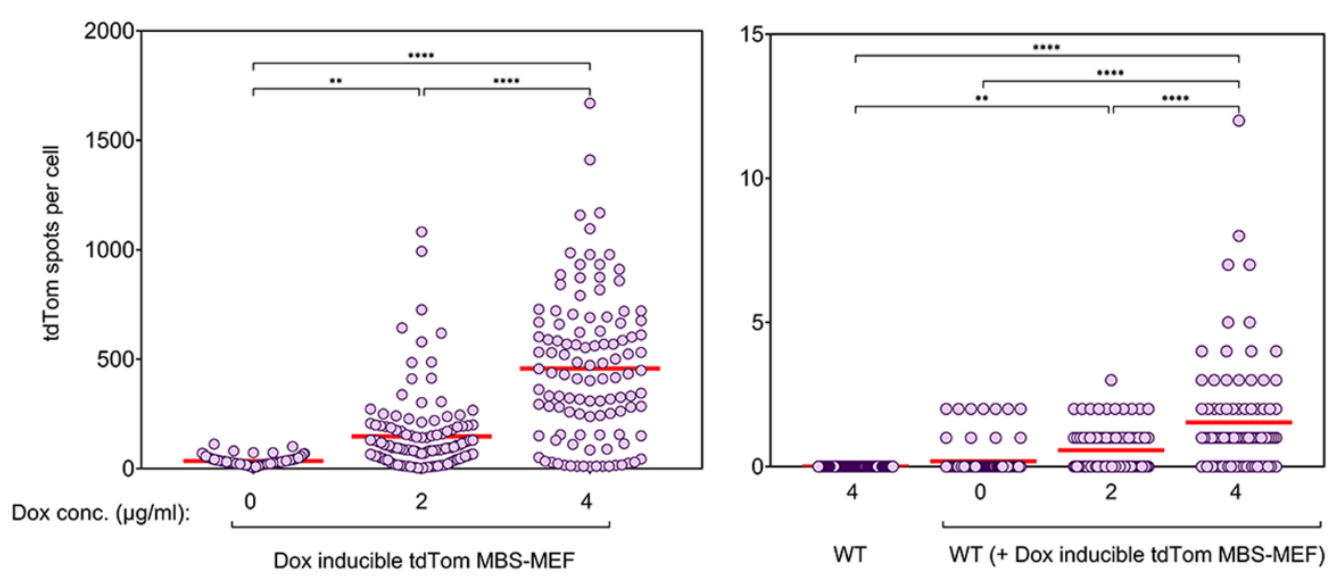

\section{Figure 5}


bioRxiv preprint doi: $\mathrm{https}$ //doi.org/10.1101/2021.1128.470233; this version posted November 28, 2021. The copyright holder for this preprint (which was not certified by peer review) is the author/funder, who has granted bioRxiv a license to display the preprint in perpetuity. It is made available under aCC-BY-NC-ND 4.0 International license.
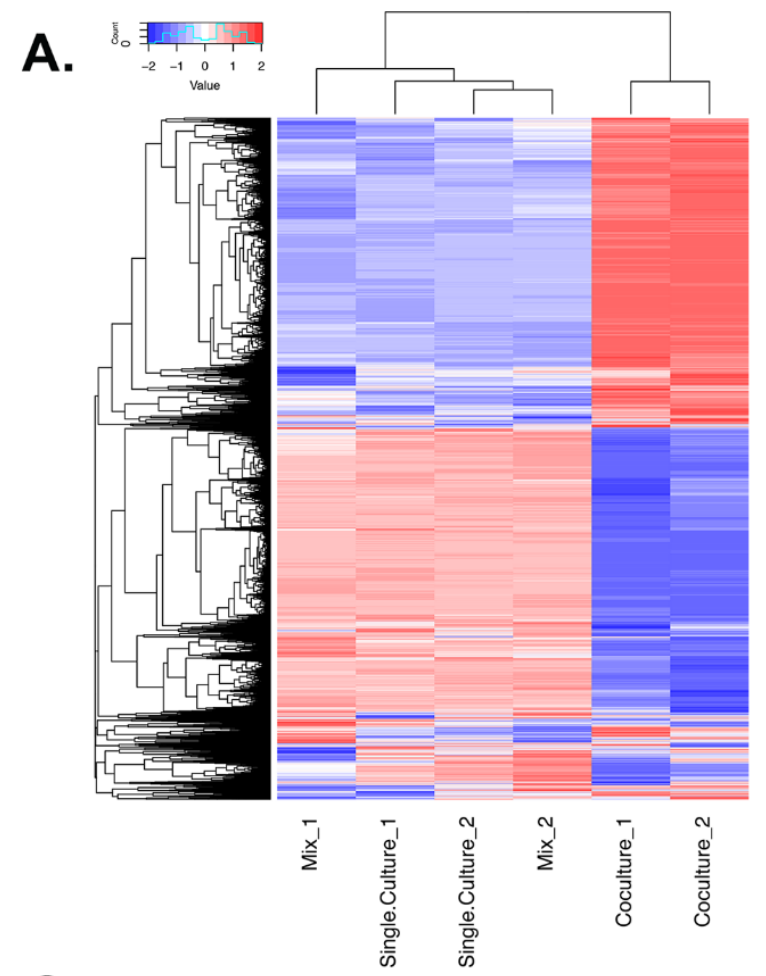

B.

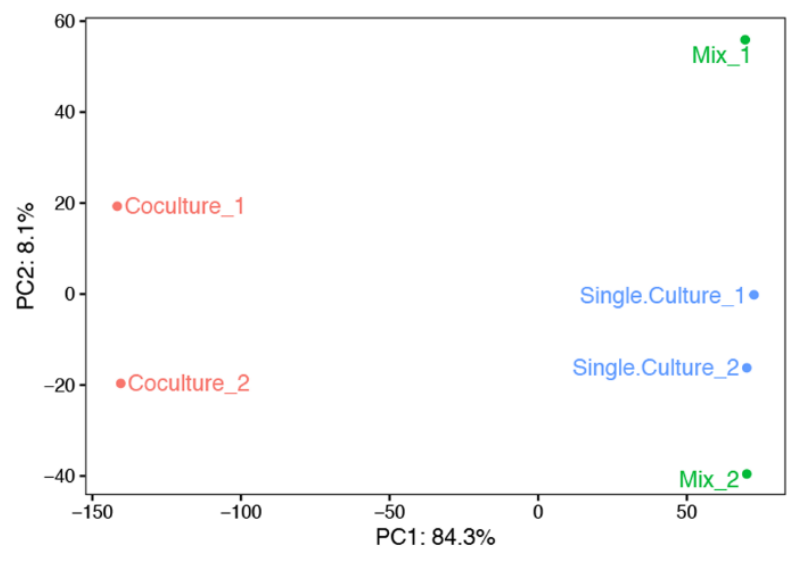

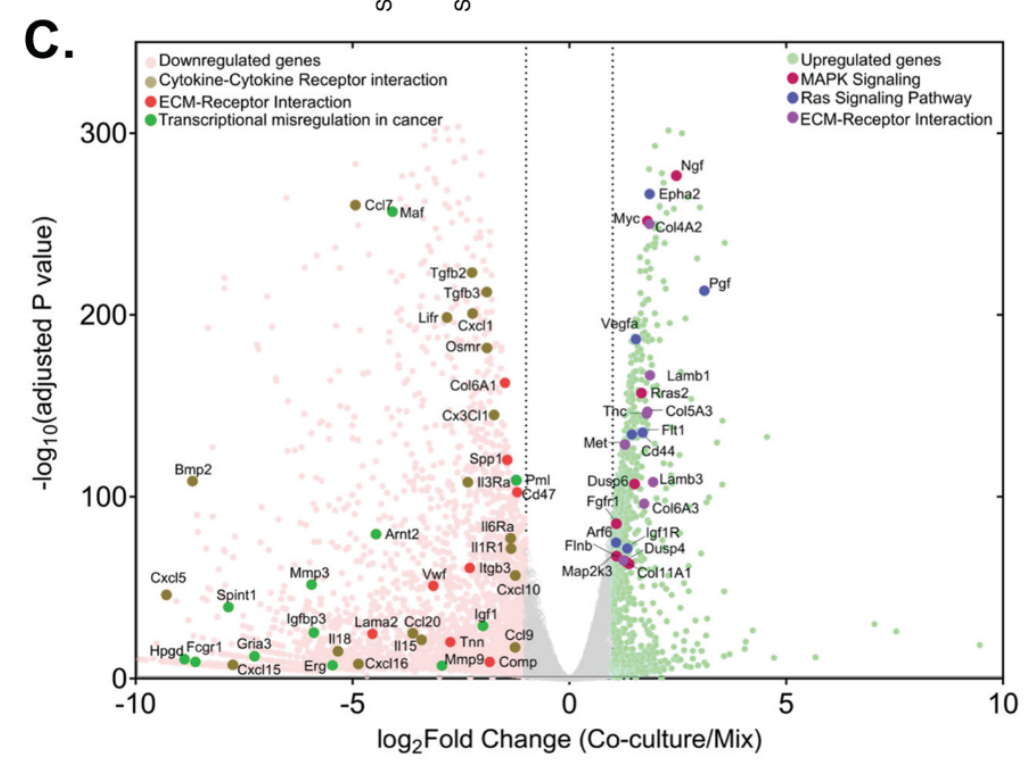

Figure 6 
bioRxiv preprint doi: https://doi.org/10.1101/2021.11.28.470233; this version posted November 28, 2021. The copyright holder for this preprint (which was not certified by peer review) is the author/funder, who has granted bioRxiv a license to display the preprint in perpetuity. It is made available under aCC-BY-NC-ND 4.0 International license.

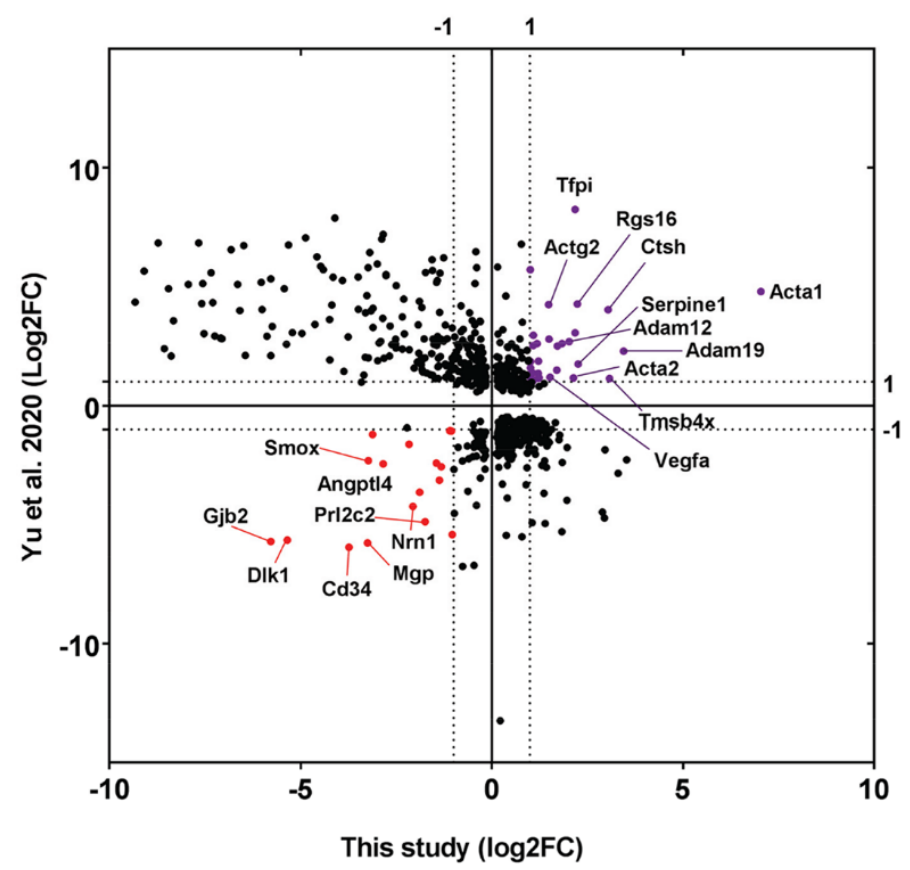

Upregulated genes that were also found to be induced in metastatic lung cancer-derived CAFs (Pein et al. Nat. Comm. 2020)

\begin{tabular}{|c|}
\hline Acta2 \\
\hline Serpine1 \\
\hline Tagln \\
\hline Serpinb6a \\
\hline Adam19 \\
\hline Acta1 \\
\hline Adam12 \\
\hline Tfpi \\
\hline Col6a3 \\
\hline
\end{tabular}

Figure 7 
bioRxiv preprint doi: $\mathrm{https}$ //doi.org/10.1101/2021.1128.470233: this version posted November 28, 2021. The copyright holder for this preprint (which was not certified by peer review) is the author/funder, who has granted bioRxiv a license to display the preprint in perpetuity. It is made available under aCC-BY-NC-ND 4.0 International license.

\section{Supplementary Figures}

A.
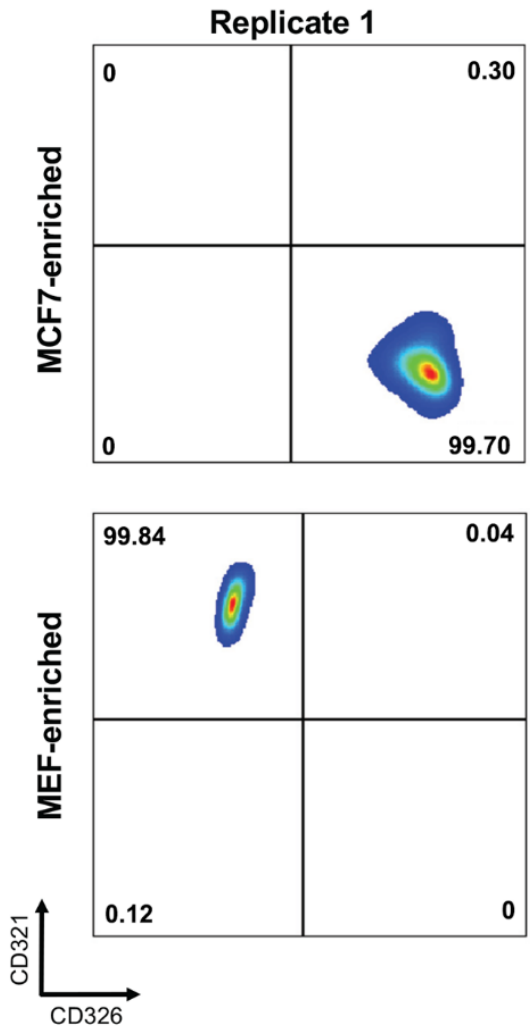

Replicate 2
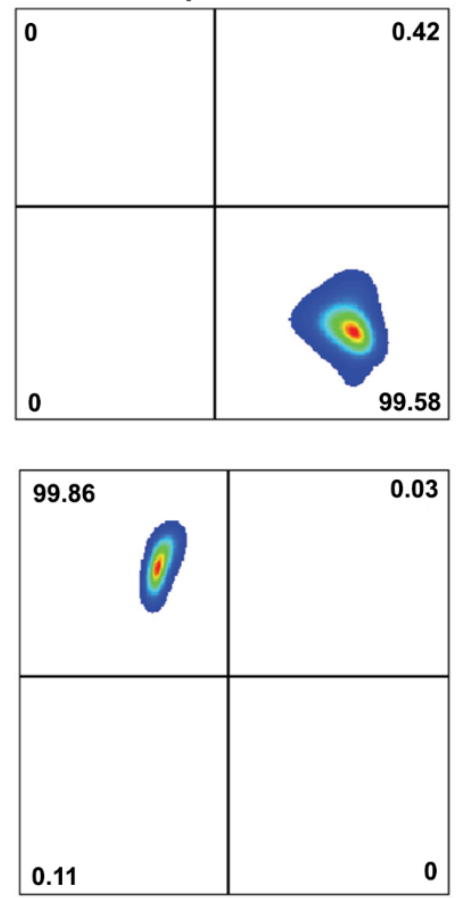

B.

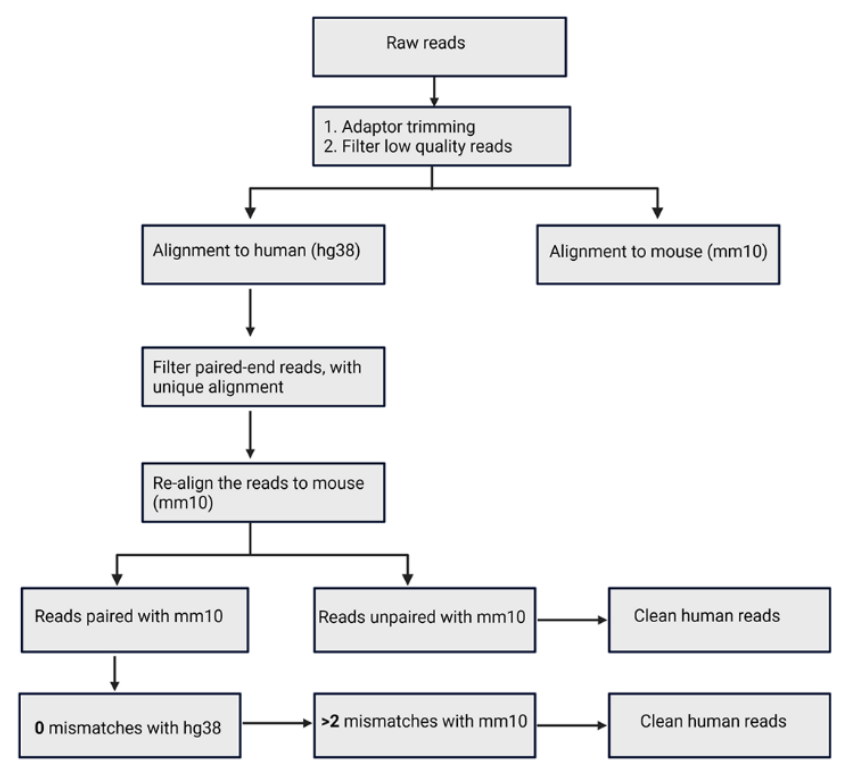

Figure S1 
bioRxiv preprint doi: https://doi.org/10.1101/2021.11.28.470233; this version posted November 28, 2021. The copyright holder for this preprint (which was not certified by peer review) is the author/funder, who has granted bioRxiv a license to display the preprint in perpetuity. It is made available under aCC-BY-NC-ND 4.0 International license.

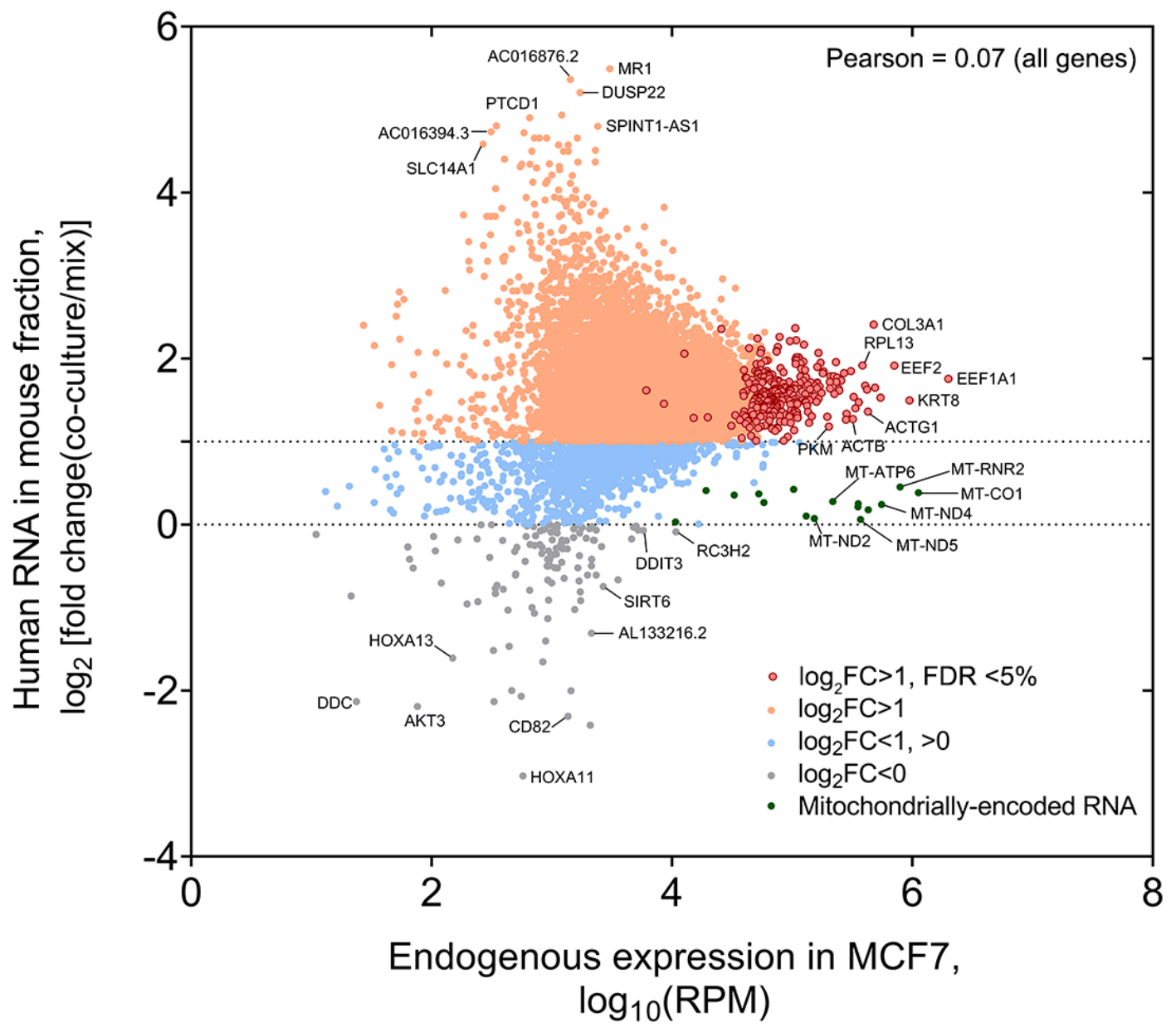

\section{Figure S2}


bioRxiv preprint doi: https://doi.org/10.1101/2021.11.28.470233; this version posted November 28, 2021. The copyright holder for this preprint (which was not certified by peer review) is the author/funder, who has granted bioRxiv a license to display the preprint in perpetuity. It is made available under aCC-BY-NC-ND 4.0 International license.

A. SRP-dependent cotranslational protein targeting to membranenuclear-transcribed mRNA catabolic process, nonsense-mediated decay viral transcription rRNA processingcell-cell adhesionmRNA splicing, via spliceosome-
cytoplasmic translationregulation of translational initiationgene expressionribosomal large subunit assemblynegative regulation of apoptotic process-

cellular response to interleukin-4viral processregulation of $M R N A$ stabilityformation of translation preinitiation complexpositive regulation of viral genome replicationribosomal small subunit biogenesisnegative regulation of translation-

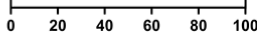

$-\log _{10}$ adjusted(p-value)

C.

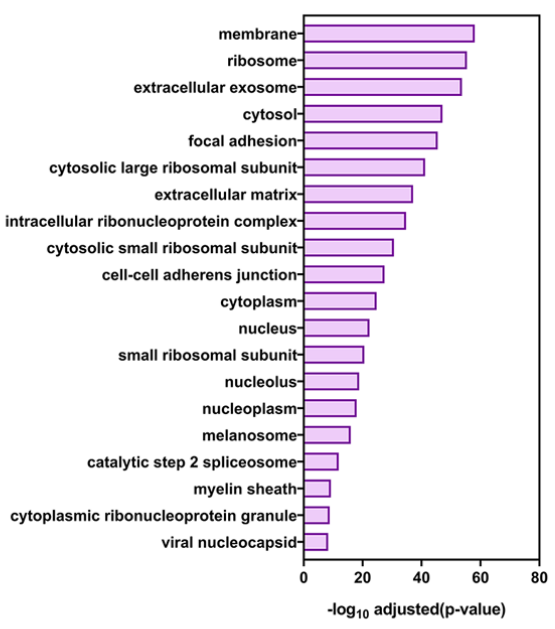

B.

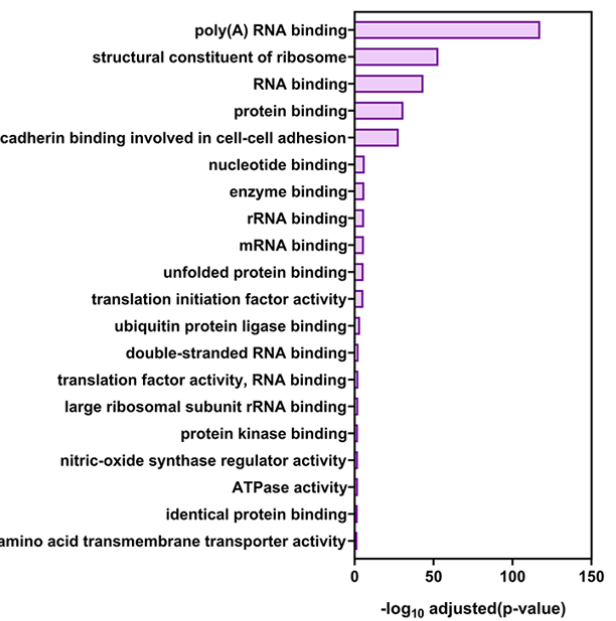

D.

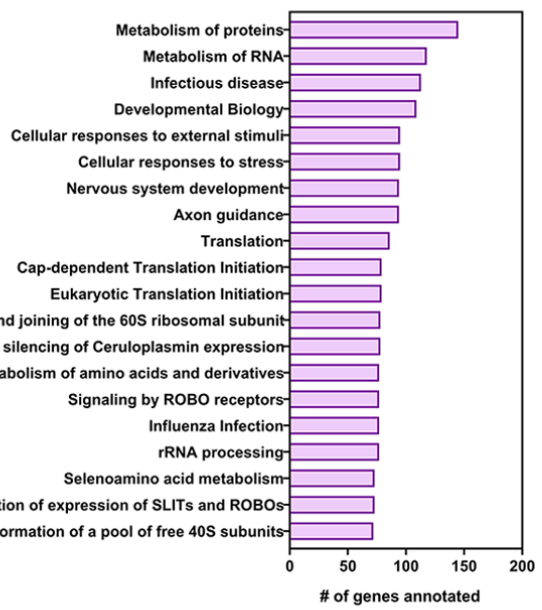

Figure S3 
bioRxiv preprint doi: https://doi.org/10.1101/2021.11.28.470233; this version posted November 28, 2021. The copyright holder for this preprint (which was not certified by peer review) is the author/funder, who has granted bioRxiv a license to display the preprint in perpetuity. It is made available under aCC-BY-NC-ND 4.0 International license.

A.

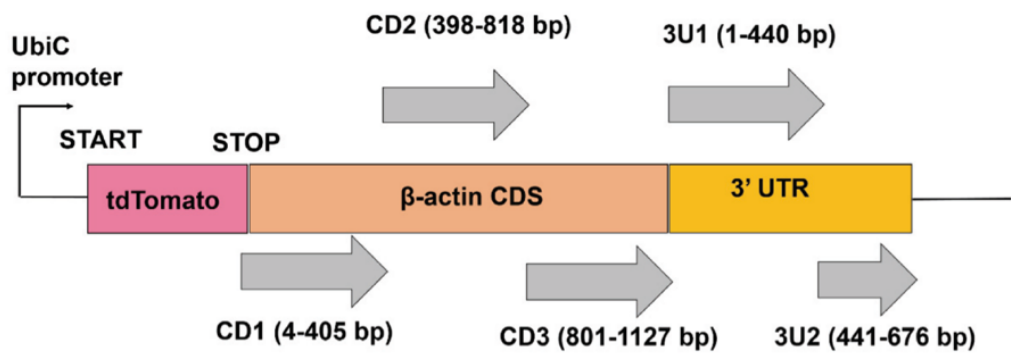

B.

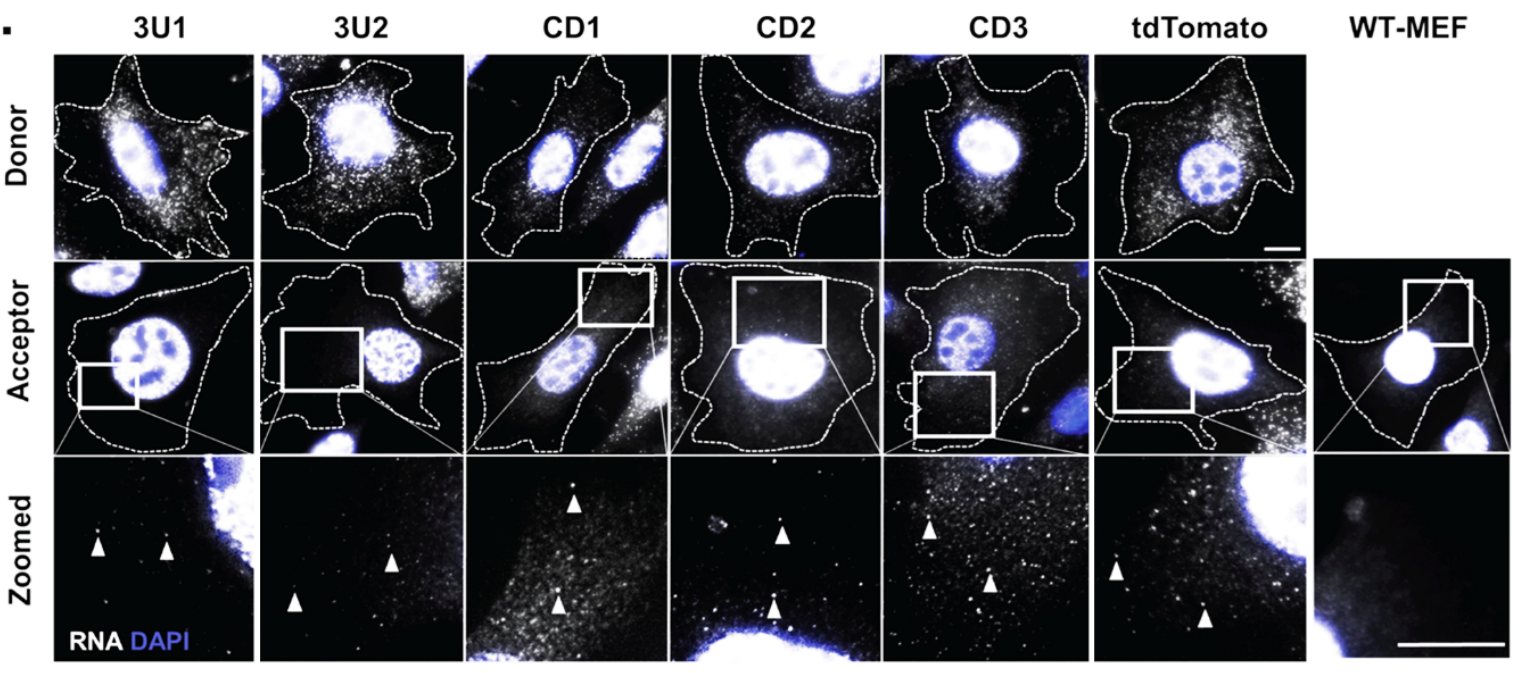

C.

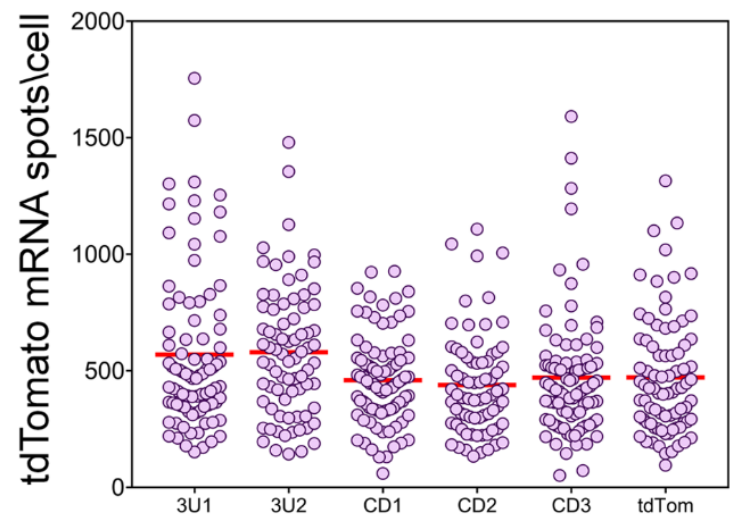

Donor MEFs

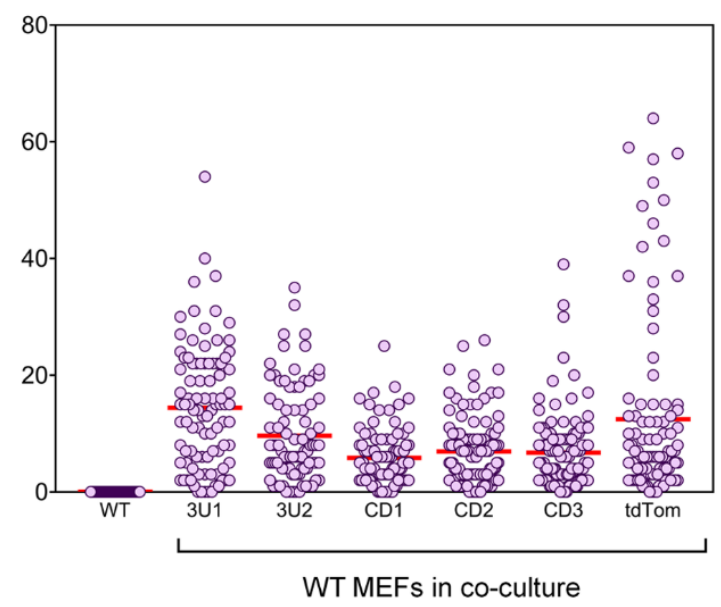

Figure S4 


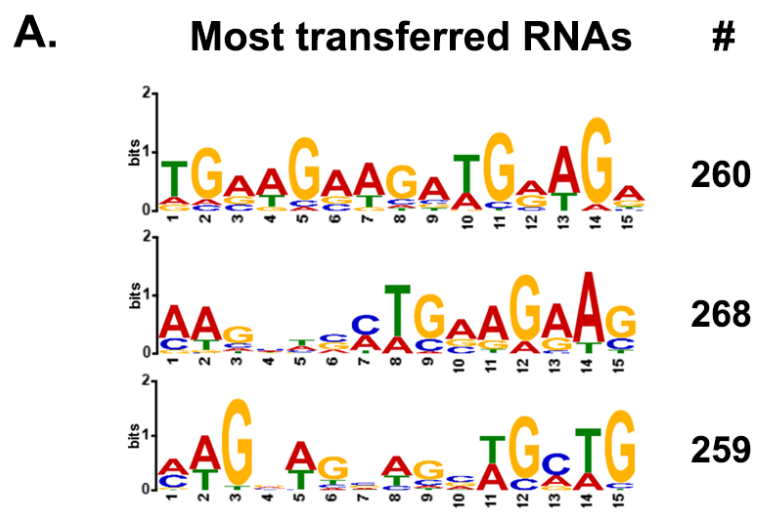

B. Least transferred RNAs

\section{Set 1}

".

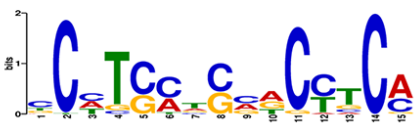

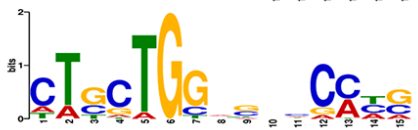

260

\#

178
Set 2

269

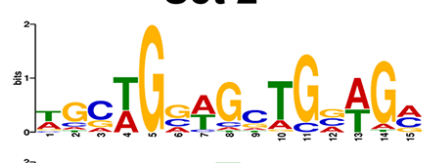

-

. A슬
Set 3

$\#$
215

222

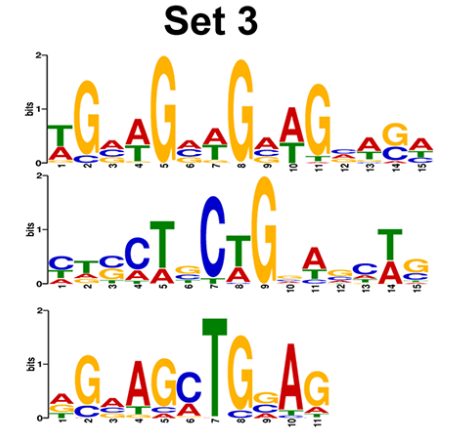

\#

238

251

226

Figure S5 
bioRxiv preprint doi: https://doi.org/10.1101/2021.11.28.470233; this version posted November 28, 2021. The copyright holder for this preprint (which was not certified by peer review) is the author/funder, who has granted bioRxiv a license to display the preprint in perpetuity. It is made available under aCC-BY-NC-ND 4.0 International license.

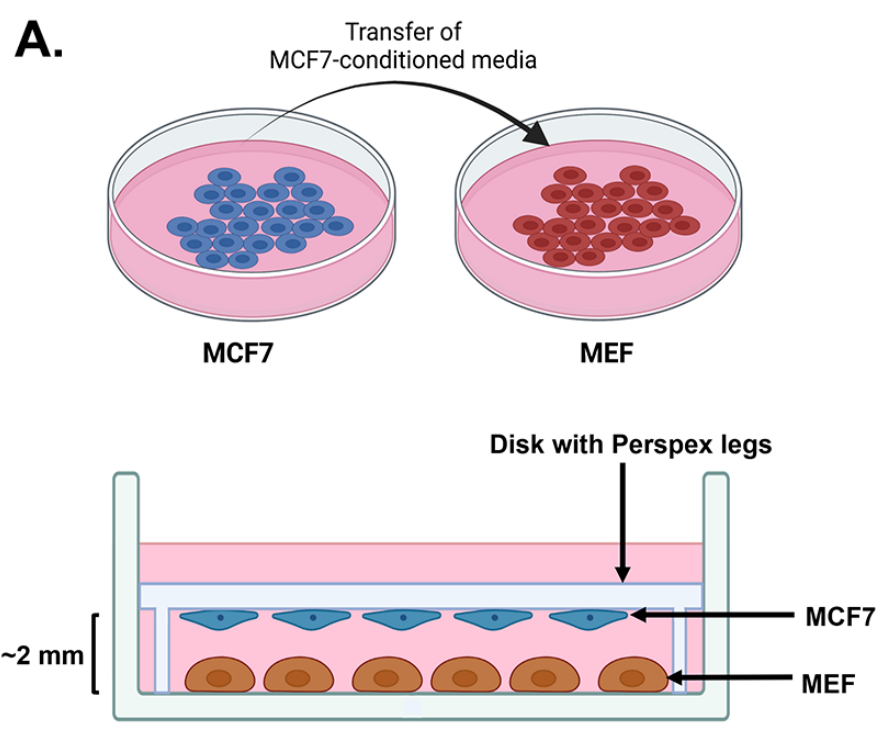

B.

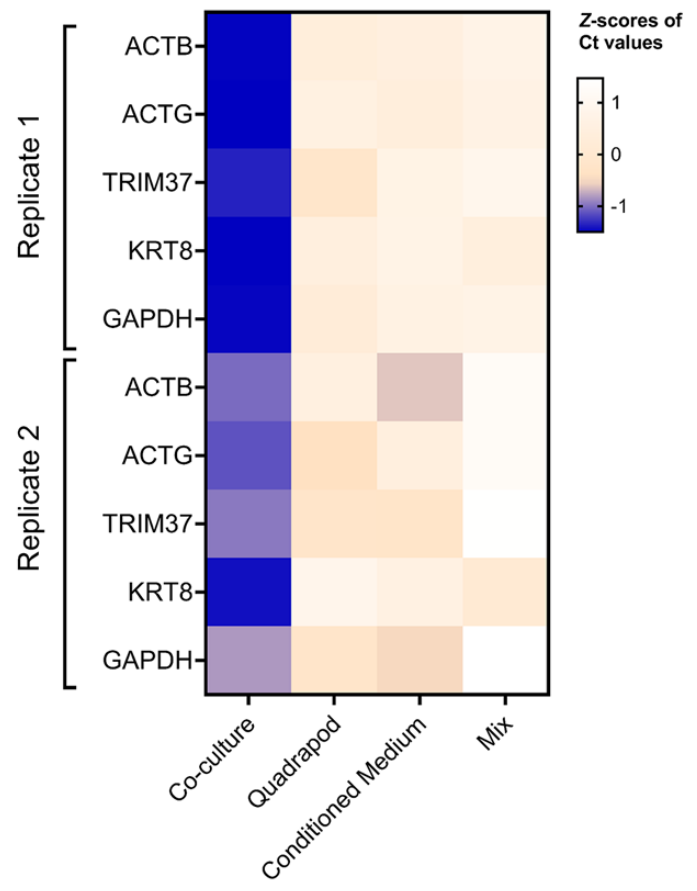

Figure S6 
bioRxiv preprint doi: https://doi.org/10.1101/2021.11.28.470233; this version posted November 28, 2021. The copyright holder for this preprint (which was not certified by peer review) is the author/funder, who has granted bioRxiv a license to display the preprint in perpetuity. It is made available under aCC-BY-NC-ND 4.0 International license.

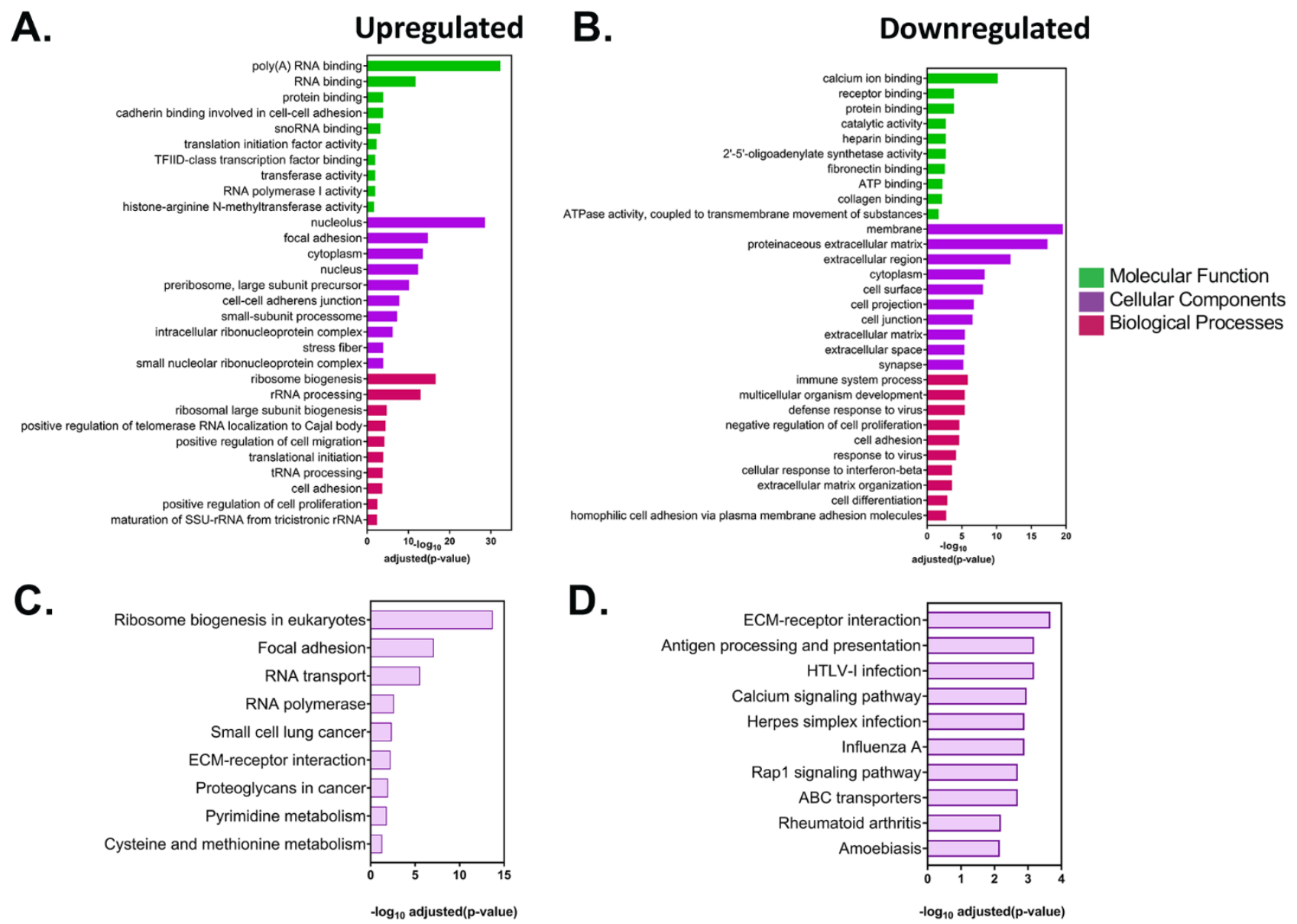

Figure S7 